Article

\title{
Experimental Study on B-Spline-Based Modulation Schemes Applied in Multilevel Inverters for Electric Drive Applications
}

\author{
Giuseppe Schettino $₫$, Guido Ala $₫$, Massimo Caruso ${ }^{\circledR}$, Vincenzo Castiglia, Filippo Pellitteri $\odot$, \\ Marco Trapanese $\mathbb{D}$, Fabio Viola * ${ }^{\mathbb{D}}$ and Rosario Miceli \\ Dipartimento di Ingegneria, University of Palermo, Viale delle Scienze, Parco d'Orleans, 90128 Palermo, Italy; \\ giuseppe.schettino@unipa.it (G.S.); guido.ala@unipa.it (G.A.); massimo.caruso16@unipa.it (M.C.); \\ vincenzo.castiglia@unipa.it (V.C.); filippo.pellitteri@unipa.it (F.P.); marco.trapanese@unipa.it (M.T.); \\ rosario.miceli@unipa.it (R.M.) \\ * Correspondence: fabio.viola@unipa.it; Tel.: +39-091-23860253
}

Received: 25 October 2019; Accepted: 26 November 2019; Published: 27 November 2019

\begin{abstract}
This work presents the design, simulation, and experimental validation of new B-Splinebased modulation techniques applied to a Multilevel Power Inverter (MPI), particularly focusing the attention on the harmonic content of the output voltages of the inverter. Simulation and experimental results are proposed and discussed, mainly describing the potential benefits, such as the increase of the multi-level operation of the converter, and drawbacks (low-order harmonics) related to the adoption of B-Spline functions for multilevel inverters applied in the field of electrical drives.
\end{abstract}

Keywords: modular multilevel converters; pulse width modulation inverters; power conversion harmonics

\section{Introduction}

In recent years, the electrical drives have reached a very wide range of industry applications, due to the significant improvement in terms of performances of both innovative electric motors and power converters. Recently, the energy consumption determined by the electrical drives corresponds to the $46 \%$ of the global energy demand [1-4] and, therefore, new optimization techniques and control algorithms have been conceived in order to either maximize the efficiency or reduce the harmonic content of the entire drive [5].

As for the power converters, the multilevel inverters represent a suitable solution especially for high-power/medium-voltage applications [6-11]. One of the advantages bought by Multilevel Power Inverters (MPI) adopted for electrical drives with respect to traditional three-phase converters is represented by the lower harmonic content of their output voltage waveform [12].

Moreover, it is well known that the traditional modulation schemes use triangular waveforms as carrier signals. In different studies the pulse-width modulation (PWM) techniques are modified in order to improve the performances of the power converter. Such improvements are mainly focused on adding specific signals on the reference signal (e.g., Switching Frequency Optimal, SFO, or Total Harmonic Injection, THI), optimizing the features of the duty-cycle $[13,14]$ or increasing the switching frequency [15-17]. In particular, the use of carrier signals with different harmonic content with respect to the triangular waveform allows changing the harmonic content in the output voltage waveform of the converter.

The B-Spline functions are commonly used in the approximation theory $[18,19]$, defined piecewise by polynomials. The first study on the modulation techniques by using B-Spline functions can be found 
in [20], which is focused on the Total Harmonic Distortion (THD\%) reduction by changing the carrier signal waveform from a traditional triangular shape to a B-Spline function, based on the interpretation of the triangular waveform as a periodic form of the second order Cardinal B-Spline function. By increasing the order of the carrier signal, the output harmonic content is reduced and, therefore, the fundamental component is improved. Nevertheless, the implementation of the B-Spline-based control algorithm is challenging, mainly due to the high execution time required for the calculation of the related functions [21,22]. Genduso et al. [23,24] presented a novel real-time algorithm that eliminated the problem concerning the B-Spline recursive evaluation through the adoption of specifically designed duty cycle expressions.

A detailed analysis regarding the spectra of the output voltage for traditional three-phase converters is reported in [25], in which it is demonstrated that the use of B-Spline-based modulation techniques increases the low-order harmonic components. With regards to the multilevel converters, there is a lack in terms of multicarrier modulation schemes based on B-Spline functions as carrier signals, where only few works are reported in literature [26,27]. Therefore, it can be stated that the adoption of B-Spline functions as carrier signals for multilevel converters has not been widely studied yet.

In this context, this work presents the design, simulation, and experimental validation of new B-Spline-based modulation techniques applied to a Cascaded H-Bridge Multilevel Inverter (CHBMI) for electric drive applications, particularly focusing the attention on the harmonic content of the output voltages of the inverter, corresponding to the supply voltages for the motor. More in detail, this paper is structured as follows: Section 2 reports a description of the B-Spline functions, whereas Section 3 presents the related modulation techniques applied for single-phase and three-phase multilevel inverters. The simulation and the experimental results are discussed in Sections 4 and 5.

\section{B-Spline Functions}

The Cardinal B-Splines adopted in this work are determined from the order-fold convolution procedure, finalized to obtain the highest order of B-Spline function. B-Spline are used in large fields of engineering and science, from the multiresolution analysis to wavelet transform and the resolution of Maxwell's equations [28-30]. In detail, the Cardinal B-Spline function of the first order, namely B1(t), by referring to a period from 0 to 1 , is defined as follows:

$$
B_{1}(t)= \begin{cases}1 & 0<t<0.5 \\ 0 & 0.5<t<1\end{cases}
$$

By adopting the procedure of order-fold convolution, the m-order Cardinal B-Spline function is defined as follows:

$$
B_{m}(t)=B_{m-1}(t) * B_{1}(t)=\int B_{m-1}(\tau) \cdot B_{1}(t-\tau) d \tau
$$

This procedure allows the obtainment of the B-Spline functions shown in Figure 1a-d.

The general m-order Cardinal B-Spline function can be converted to a periodic function:

$$
P B_{m}(t)=\left\{\begin{array}{ccc}
B_{m}(t) & \text { if } & 0<t<\frac{T}{2} \\
-B_{m}\left(t-\frac{T}{2}\right) & \text { if } & \frac{T}{2}<t<T
\end{array},\right.
$$

where $\mathrm{PBm}(\mathrm{t})$ is the periodic form of the cardinal B-Spline $\mathrm{Bm}(\mathrm{t})$ and $\mathrm{T}$ is the period of the periodic B-Spline function. The periodic functions referred to the first, second, third and fourth-order Cardinal B-Splines with their related harmonic spectra are shown in Figures 2-5, respectively. From these characteristics, it can be noticed that the $\mathrm{PB}_{2}$ function is represented by the traditional triangular waveform commonly used in the classic modulation techniques. Moreover, the comparison between the proposed trends reveals the different harmonic content for each of the plotted B-Spline functions, leading, therefore, to the presence of different harmonic components in terms of output voltages. 


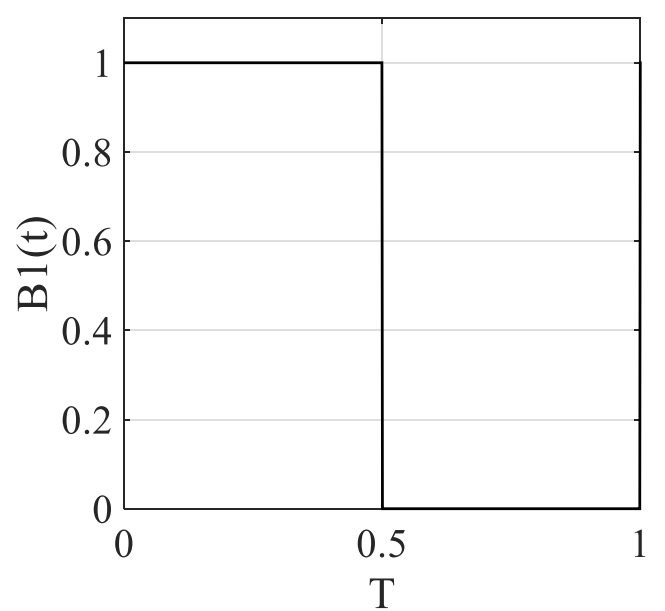

(a)

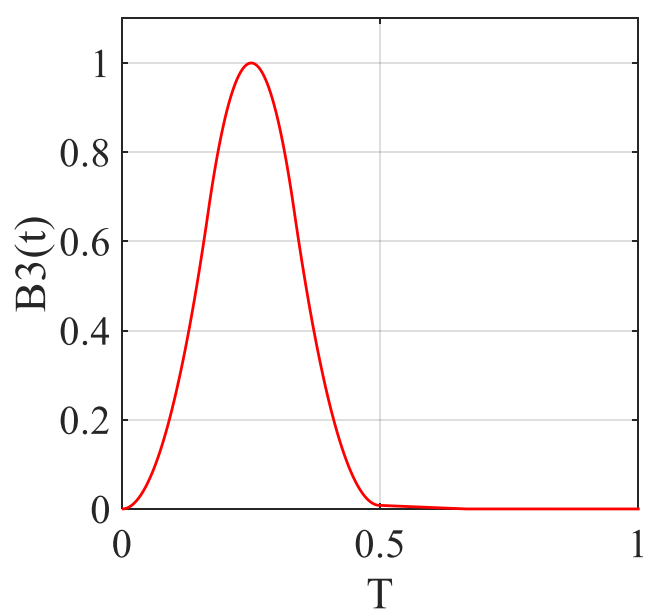

(c)

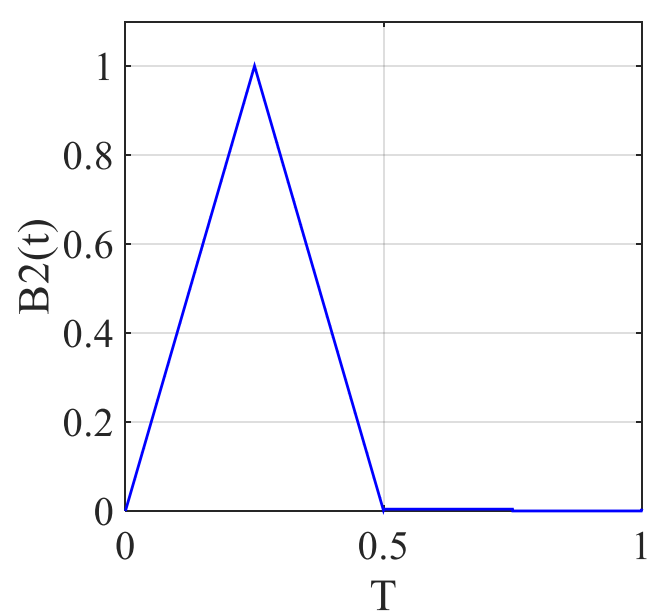

(b)

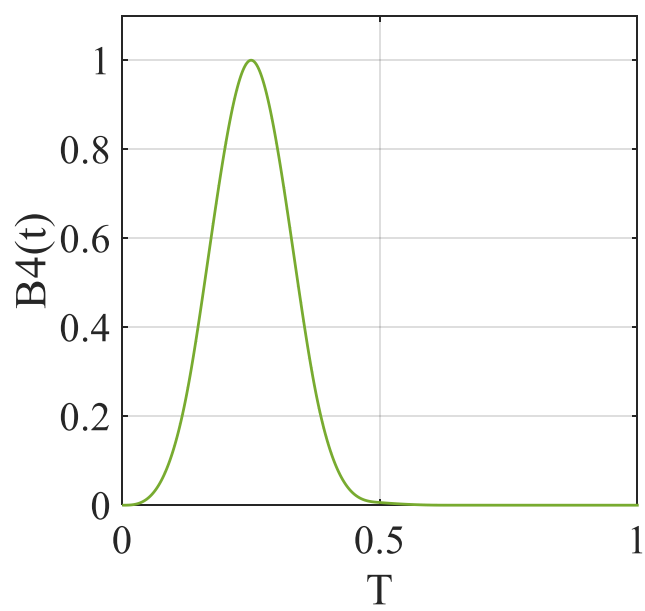

(d)

Figure 1. Cardinal B-Spline functions obtained by means of the convolution procedure: (a) first order; (b) second order; (c) third order; and (d) fourth order.

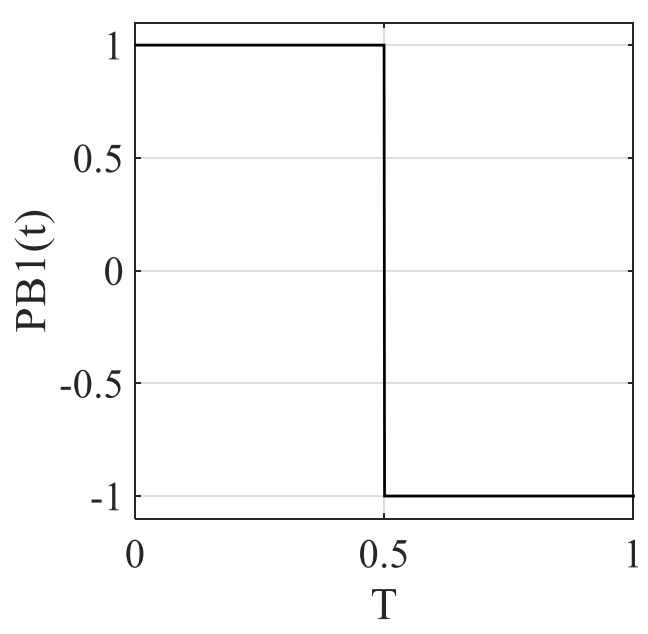

(a)

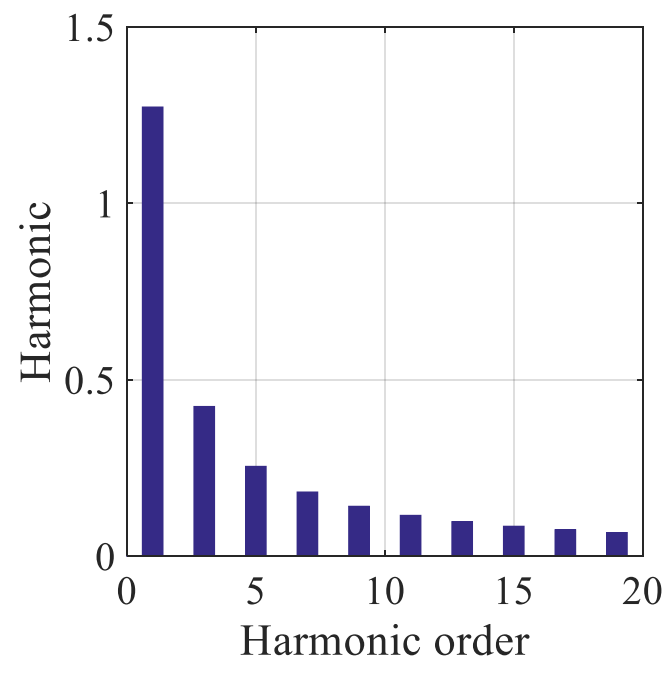

(b)

Figure 2. First order periodic B-spline function, (a) temporal representation of the function and (b) related harmonic spectrum. Sometimes named Haar function. 


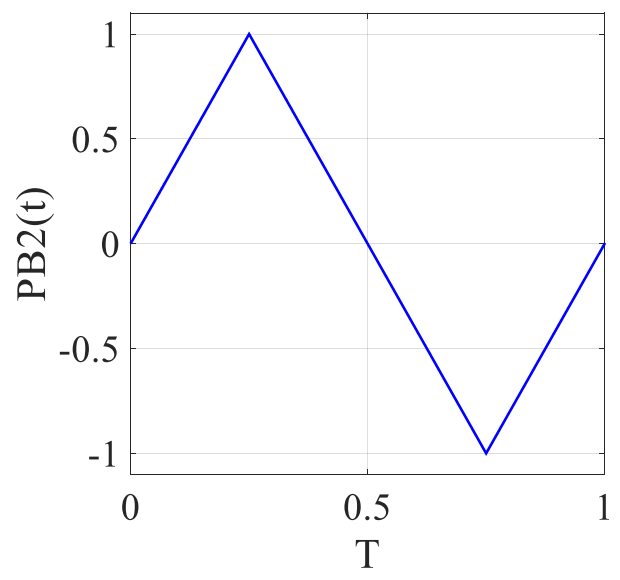

(a)

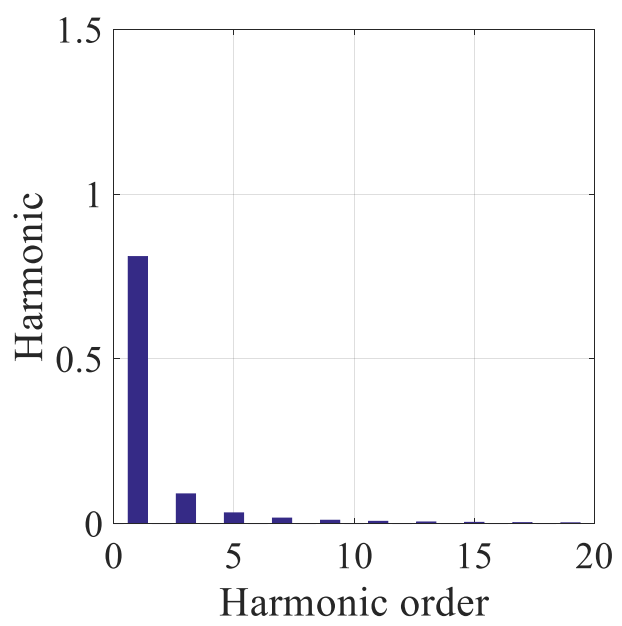

(b)

Figure 3. Second order periodic B-Spline function, (a) temporal representation of the function and (b) related harmonic spectrum.

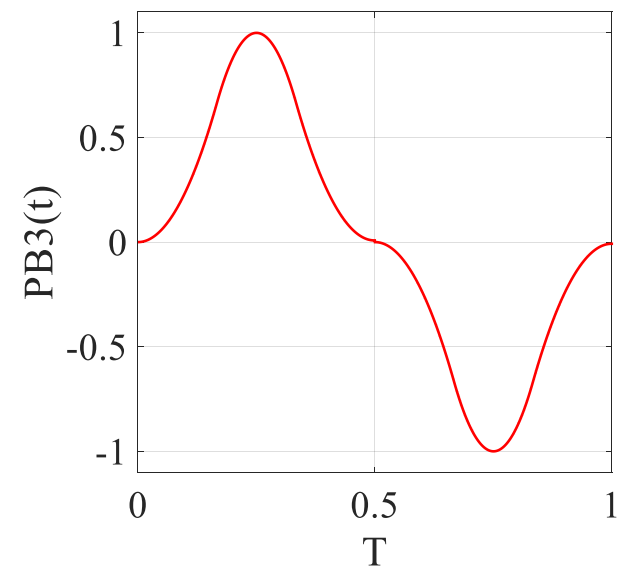

(a)

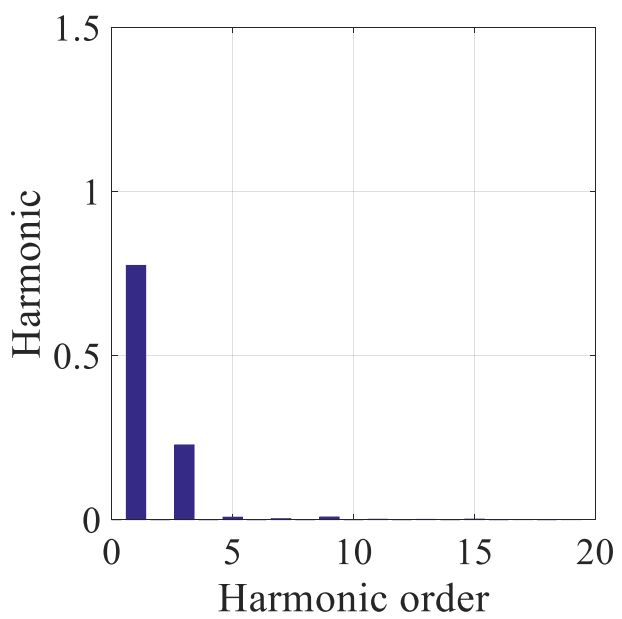

(b)

Figure 4. Third order periodic B-Spline function, (a) temporal representation of the function and (b) related harmonic spectrum.

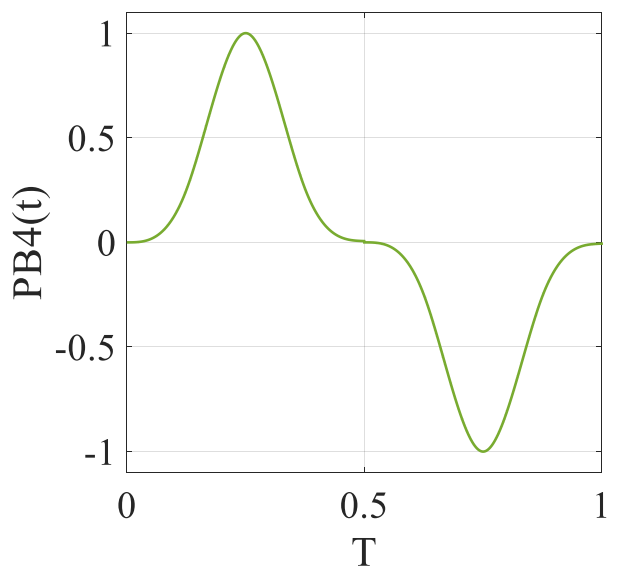

(a)

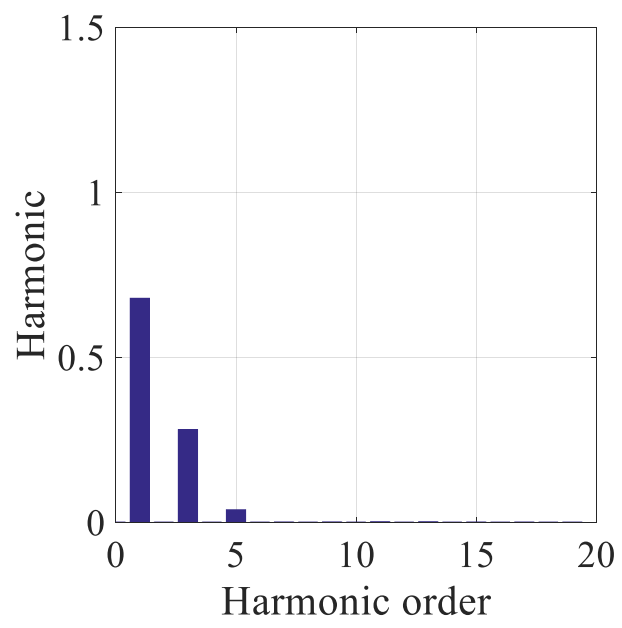

(b)

Figure 5. Fourth order periodic B-Spline function, (a) temporal representation of the function and (b) related harmonic spectrum. 
The progressive reduction of the order of harmonics, with the increase in the order of derivability of the function used, has been explored in many fields of electrical engineering [30-34].

\section{B-Spline Based Modulation Schemes for Single-Phase and Three-Phase Multilevel Inverters}

This section describes the new B-Spline-based multicarrier modulation techniques applied both for single-phase and three-phase multilevel converters, capable of supplying both single-phase and three-phase electrical motors $[26,27]$.

\subsection{Single-Phase Multilevel Inverters}

Generally, the multicarrier modulation schemes can be defined in dependence of both the reference and the carrier signals. In particular, the Authors of [35-37] presented four different techniques strictly related to the carrier signals: Phase Disposition (PD), Phase Opposition Disposition (POD), Alternative Phase Opposition Disposition (APOD), and Phase Shifted (PS). For each technique, the proposed modulation schemes with third order $\left(\mathrm{PB}_{3}\right)$ and fourth order $\left(\mathrm{PB}_{4}\right) \mathrm{B}-\mathrm{Spline}$ functions with sinusoidal reference are shown in Figures 6 and 7, respectively, obtaining eight new multicarrier modulation schemes.

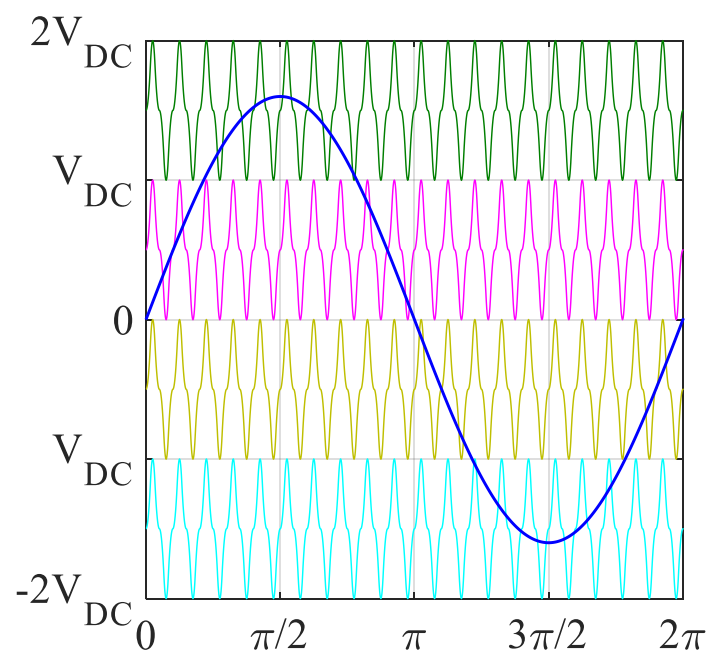

(a)

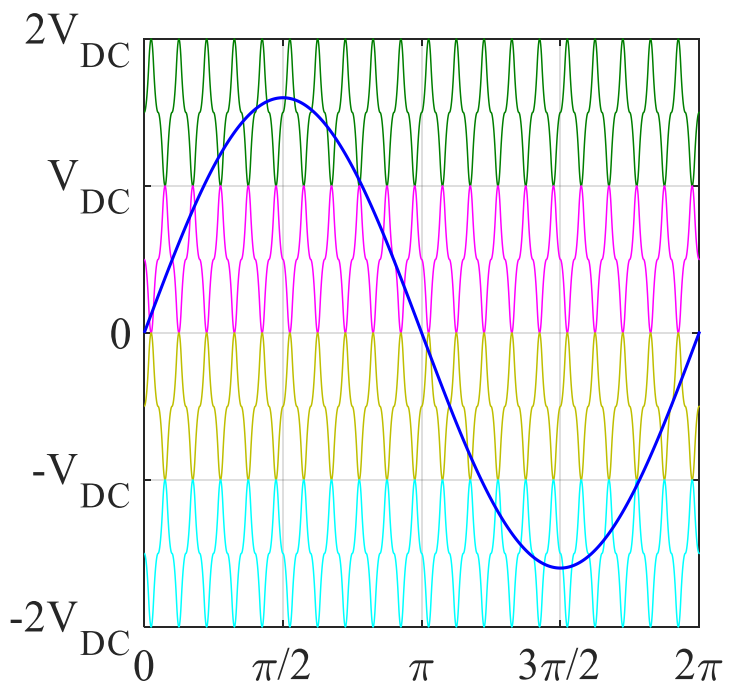

(c)

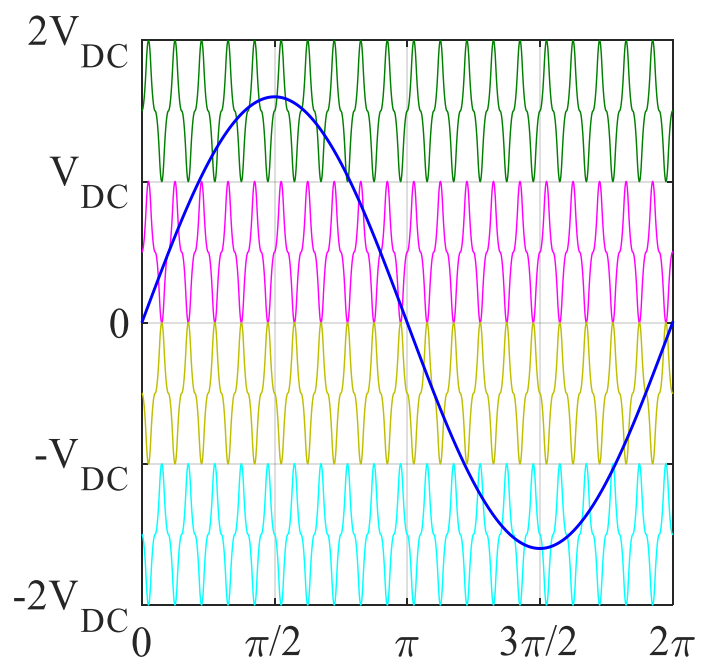

(b)

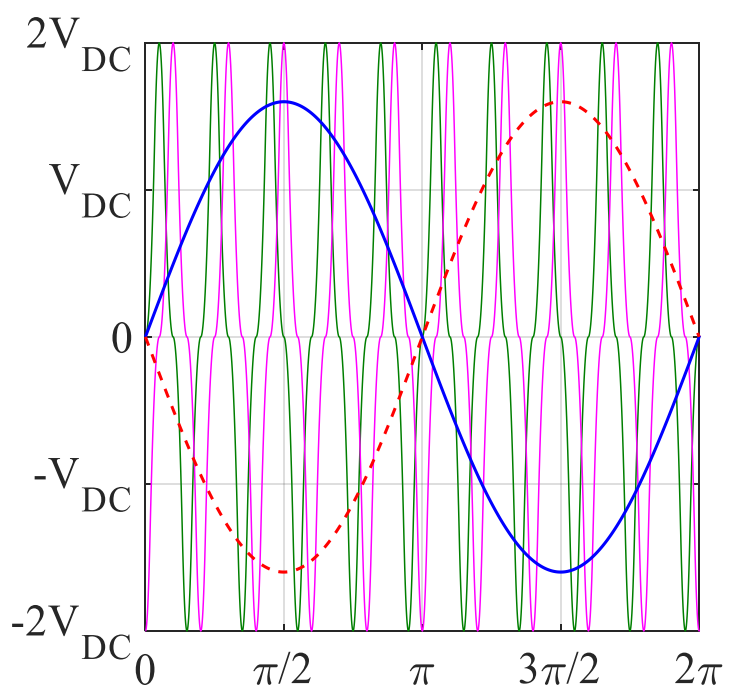

(d)

Figure 6. Third order B-spline-based modulation schemes: (a) PD, (b) POD, (c) APOD, and (d) PS. 


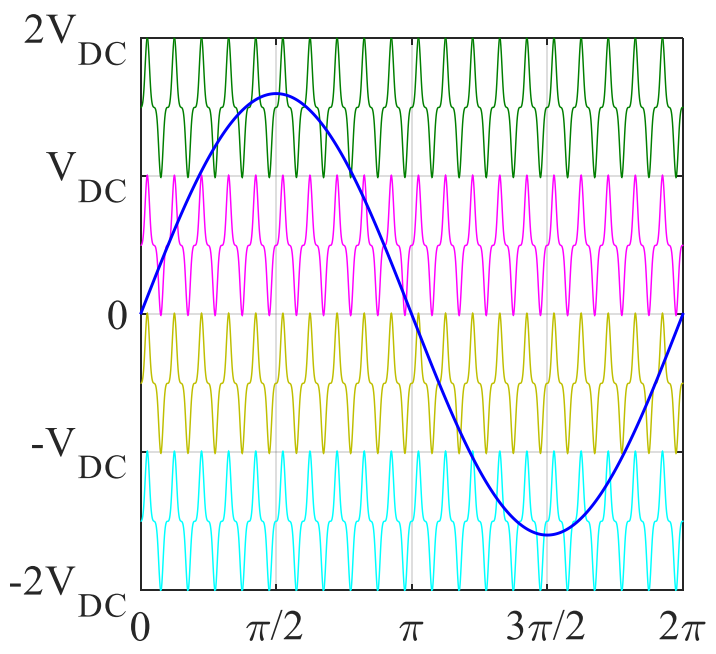

(a)

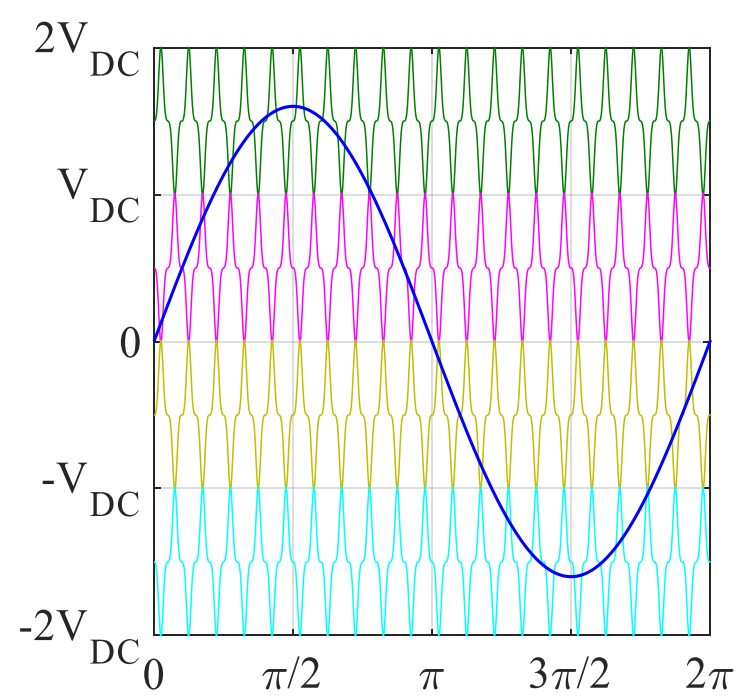

(c)

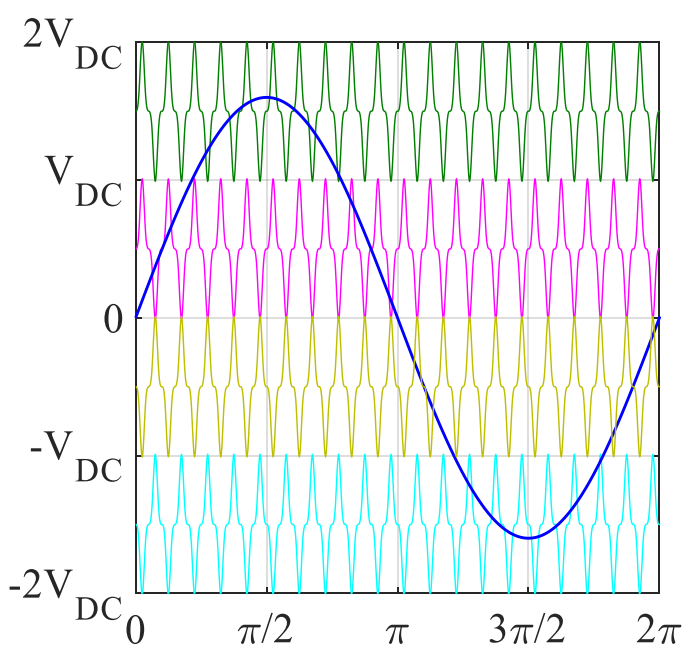

(b)

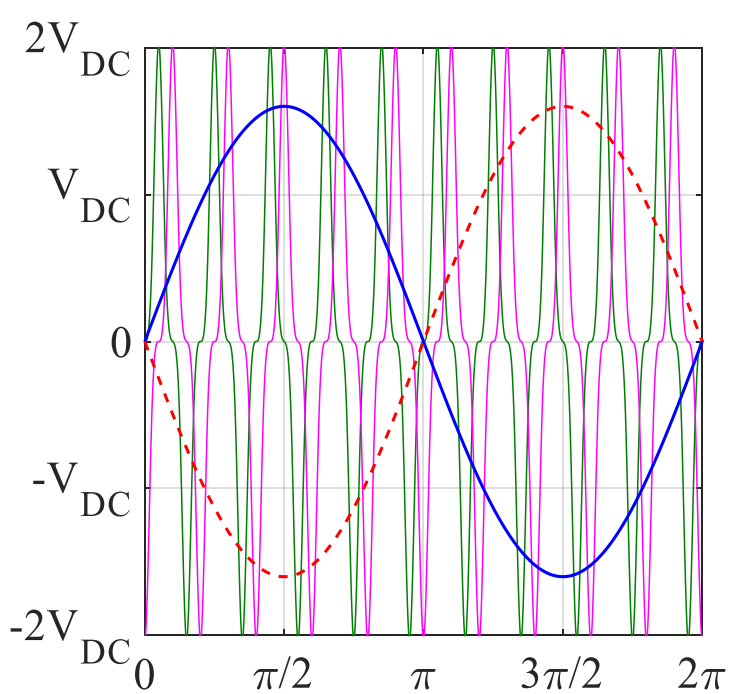

(d)

Figure 7. Fond urth order B-spline-based modulation schemes: (a) PD, (b) POD, (c) APOD, (d) PS.

With respect to the traditional modulation schemes, the intersection between the reference and the carrier signals is different and, therefore, different harmonic components and distinctive values of THD $\%$ for each modulation scheme are expected.

With regards to the Sinusoidal PS, this technique is characterized by two triangular waveforms as carrier signals with mutual phase shift equal to $\pi / 2$ and with related intersection at a half of the peak value. Thus, these intersections represent the change of operation of the converter from three levels to five levels. Figure 8 shows the comparison between the PS carrier signals for a five-level converter obtained with $\mathrm{PB}_{2}$ (blue curves), $\mathrm{PB}_{3}$ (red curves), and $\mathrm{PB} 4$ (green curves). It can be noticed that the intersection points among the carrier signals (signed with purple circles) is different for each technique and, particularly, it is lower for $\mathrm{PB}_{3}$ and $\mathrm{PB}_{4}$ (equal to 0.37 and 0.26 , respectively). Thus, if compared with $\mathrm{PB}_{2}$, the five-level voltage will appear for lower values of the modulation index. 


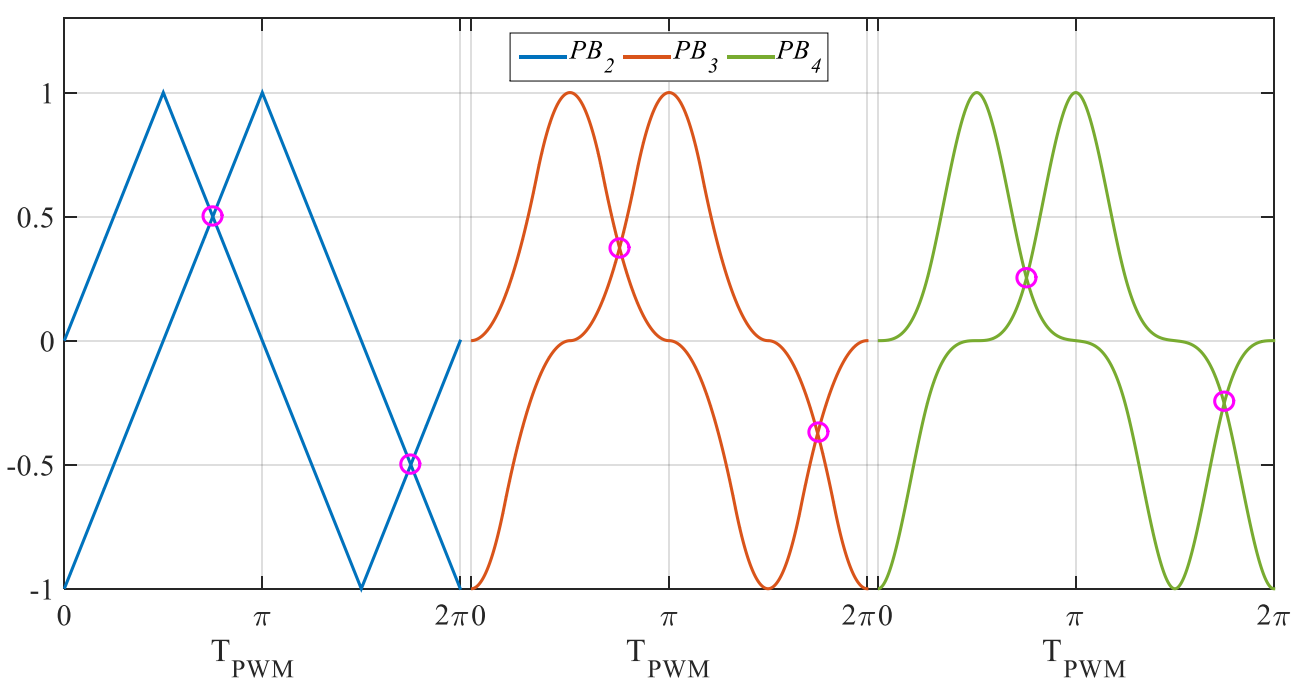

Figure 8. Comparison between the intersections of PS carrier signals for a five-level converter. In traditional modulation scheme with triangle waveform as carrier signals (PB2) the transition from three to five levels occurs for modulation index equal to 0.5. By using the B-spline functions as carrier signals (PB3 and PB4), this transition is achieved for lower values of the modulation index, equal to 0.37 and 0.26 for PB3 and PB4, respectively.

\subsection{Three-Phase Multilevel Inverters}

The new B-Spline-based modulation techniques for three-phase inverters represent the evolution of the schemes previously described and referred to single-phase topologies. Specifically, these techniques adopt PS as carrier signals and different reference signals, such as reported in [27].

The first modulation schemes take into account a three-phase sinusoidal reference with $S P B_{3}$ and $\mathrm{SPB}_{4}$ B-Spline functions, as plotted in Figure 9a,b, respectively. Other modulation schemes can be obtained by combining a THI reference signal with the third and fourth order B-Spline functions, as shown in Figure 10a,b. Finally, Figure 11 shows the modulation schemes based on the combination of an SFO reference signal with the $P B_{3}$ and $P B_{4}$ functions.

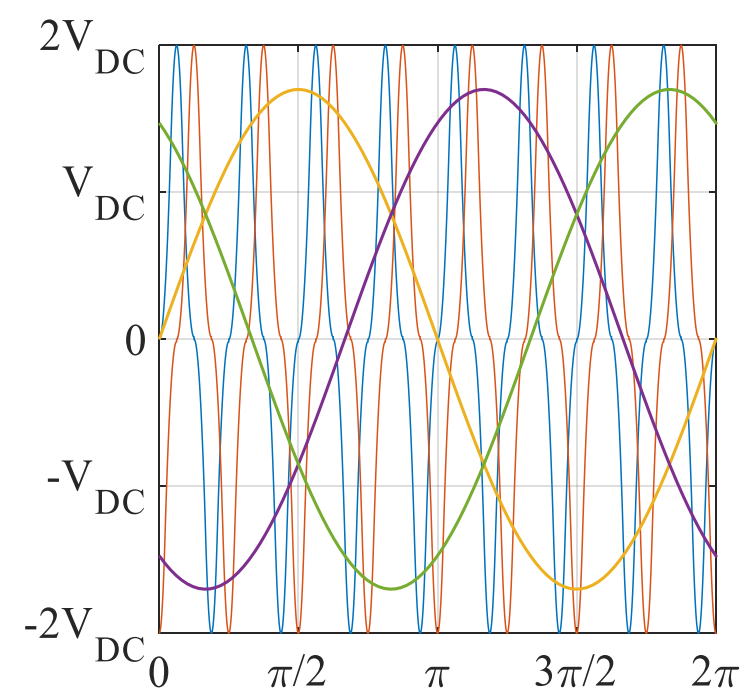

(a)

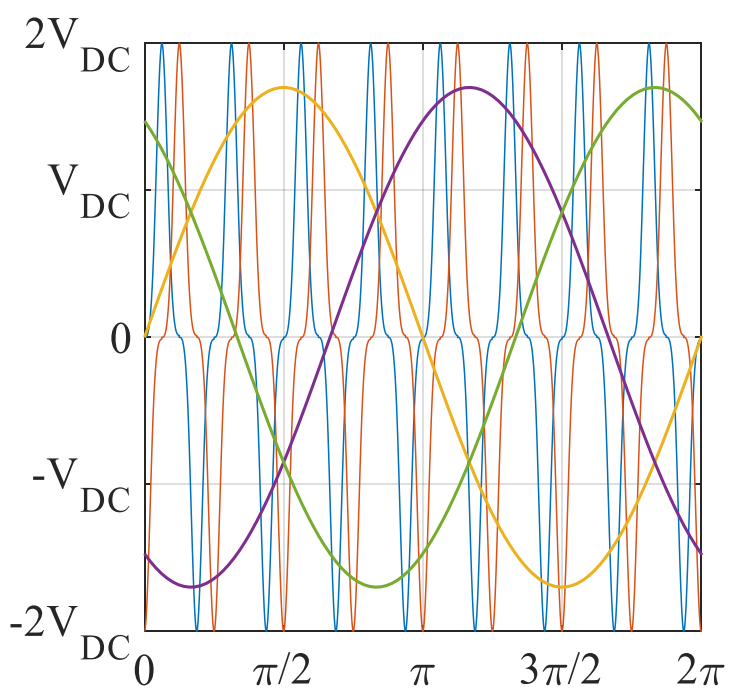

(b)

Figure 9. Modulation schemes with sinusoidal reference, the three different phases are sketched in green, yellow and purple, blue and orange are used for the carriers employing periodic B-spline function: (a) SPB3 and (b) SPB4. 


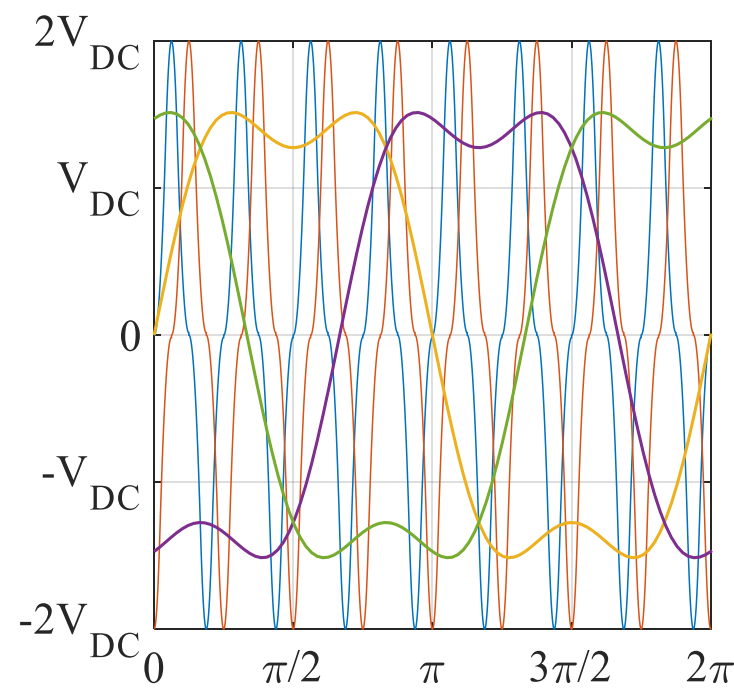

(a)

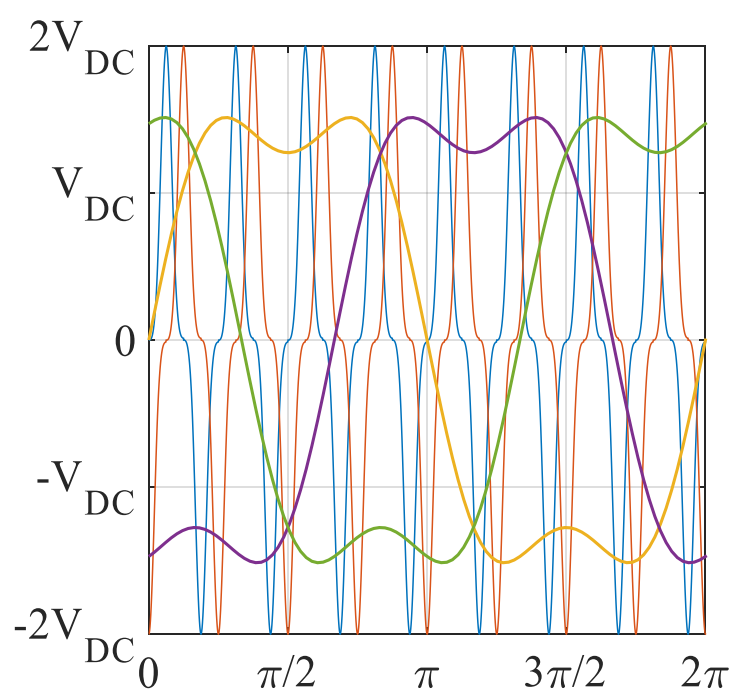

(b)

Figure 10. Modulation schemes with Total Harmonic Injection (THI) reference for each phase (green, yellow and purple): (a) SPB3 and (b) SPB4.

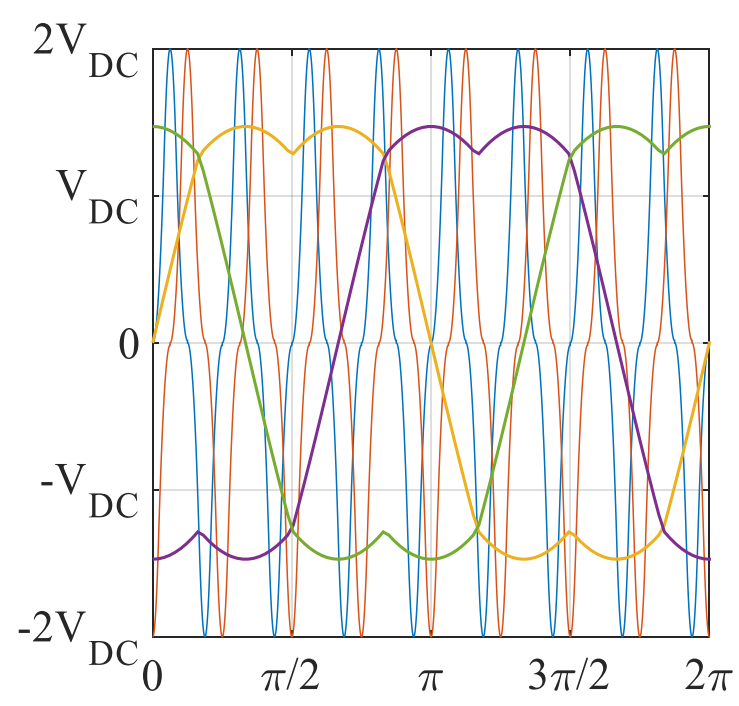

(a)

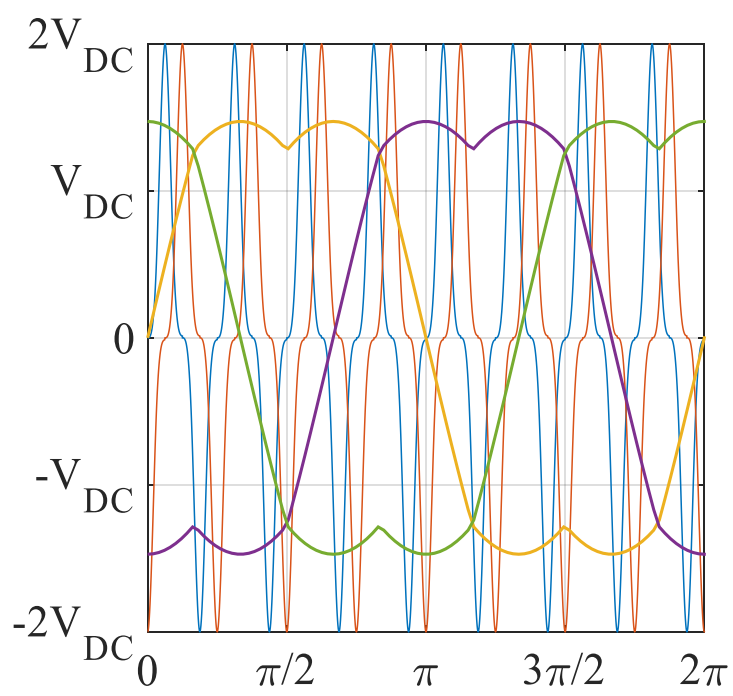

(b)

Figure 11. Modulation schemes with Switching Frequency Optimal, (SFO) reference for each phase (grren, yellow and purple): (a) SPB3 and (b) SPB4.

In conclusion, the B-spline based modulation schemes for single-phase and three-phase multilevel inverters have been presented in this section. In the next section, simulation results and discussions are reported.

\section{Simulation Results and Discussion}

This section provides the simulation results obtained by implementing the modulation techniques previously reported in Section 3 for both single-phase and three-phase inverters. In particular, the main purpose of this analysis is the determination of the harmonic content on the output voltage of the converter for each of the proposed new modulation schemes. The comparison between these techniques has been achieved by considering the Total Harmonic Distortion (THD\%) for different 
values of the modulation index $\mathrm{M}$, in order to determine the best solution in terms of harmonic content. The THD\% parameter can be defined as follows:

$$
T H D \%=\sqrt{\frac{V_{r m s}^{2}-V_{r m s, 1}^{2}}{V_{r m s, 1}^{2}}} \cdot 100 .
$$

where $V_{r m s}$ is the root mean square (rms) value of the phase voltage and $V_{r m s, 1}$ is the rms value of its fundamental harmonic. As for the three-phase topology, the THD\% line voltage has been considered. The simulations have been carried out by means of the Matlab-Simulink ${ }^{\circledR}$ environment with the simulation parameters reported in Table 1.

Table 1. Simulation parameters.

\begin{tabular}{ccc}
\hline Quantity & Symbol & Value \\
\hline Reference frequency & $f$ & $50 \mathrm{~Hz}$ \\
Switching frequency & $f_{P W M}$ & $10 \mathrm{kHz}$ \\
Frequency modulation index & $m_{f}$ & 200 \\
DC Voltage & $V_{D C}$ & $100 \mathrm{~V}$ \\
Voltage level & $l$ & \\
\hline
\end{tabular}

\subsection{Single-Phase Multilevel Inverters}

For the simulation analysis, a single-phase, five-level, Cascaded H-Bridge Multilevel Inverter (CHBMI) has been simulated, whose parameters are reported in Table 1.

The computed THD\% values as function of $\mathrm{M}$ for the phase voltage are plotted in Figure 12a-d. It can be noticed that the THD\% obtained for the PD (see Figure 12a), POD (see Figure 12b) and APOD (see Figure 12c), for different values of the reference voltage, are similar to each other and almost independent from the considered periodic B-Spline function. Only light differences can be detected, especially for low modulation indexes. Nevertheless, as shown in Figure 12d, significant differences in terms of THD\% can be detected between the B-Spline functions by adopting the PS as carrier signal. In particular, for $\mathrm{M}$ in the range of [0.2 0.6], $P B_{3}$ and $P B_{4}$ present a lower value of THD\% with respect to the $P B_{2}$, which represents the traditional triangular reference waveform. Therefore, this fact leads to a relevant advantage on the adoption of B-Spline functions, especially for variable-speed electrical drives, such as in automotive applications.

In addition, the comparison between the trends of the fundamental amplitude (peak value) of $P B_{2}$, $P B_{3}$, and $P B_{4}$ as function of $\mathrm{M}$ obtained with PD, POD, APOD, and PS are plotted in Figure 13a-d), respectively. It can be noticed that the trends obtained with $P B_{3}$ and $P B_{4}$ are not linear. Furthermore, the fundamental harmonic amplitudes obtained for PD (see Figure 13a), POD (see Figure 13b) and APOD (see Figure 13c) present similar values between the considered periodic B-Spline functions. Nevertheless, the adoption of the PS technique (see Figure 13d) contributes to an evident boost effect on the fundamental amplitude with $P B_{3}$ and $P B_{4}$ and this effect is higher for lower values of the modulation index. 


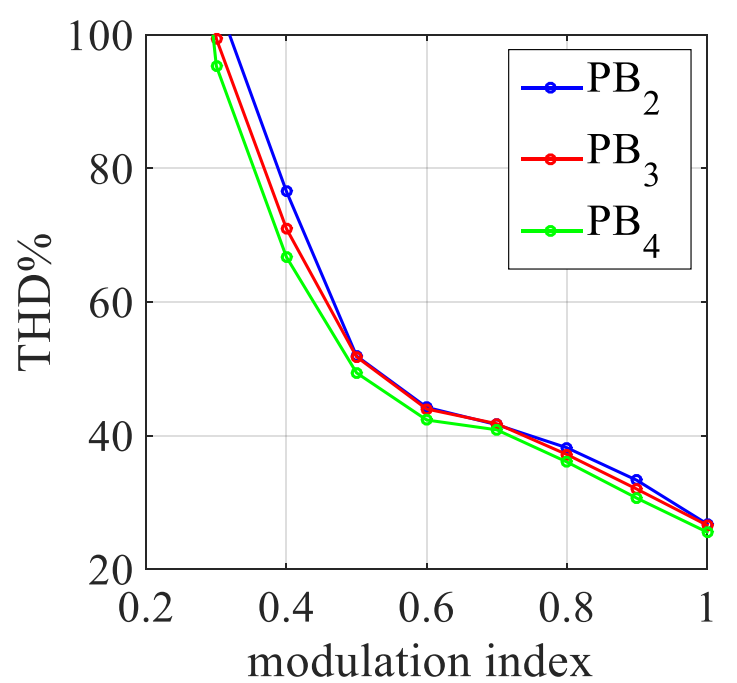

(a)

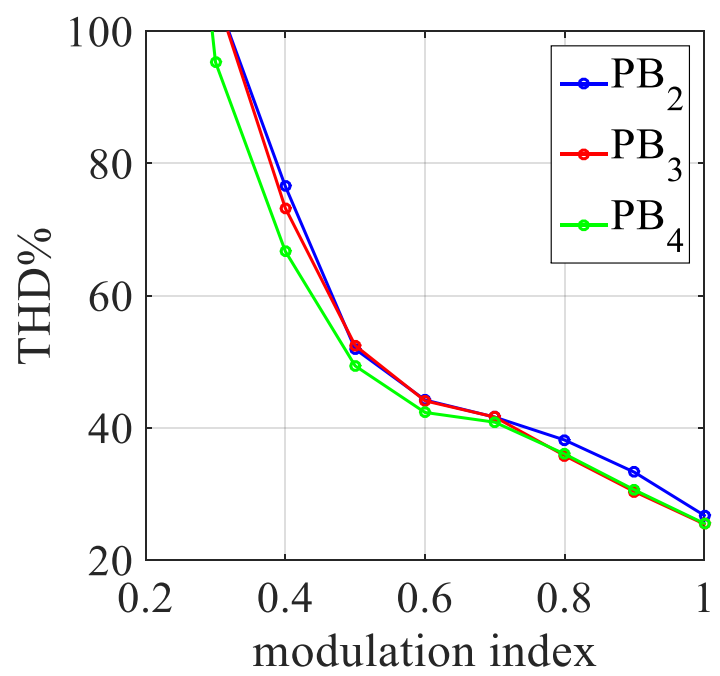

(c)

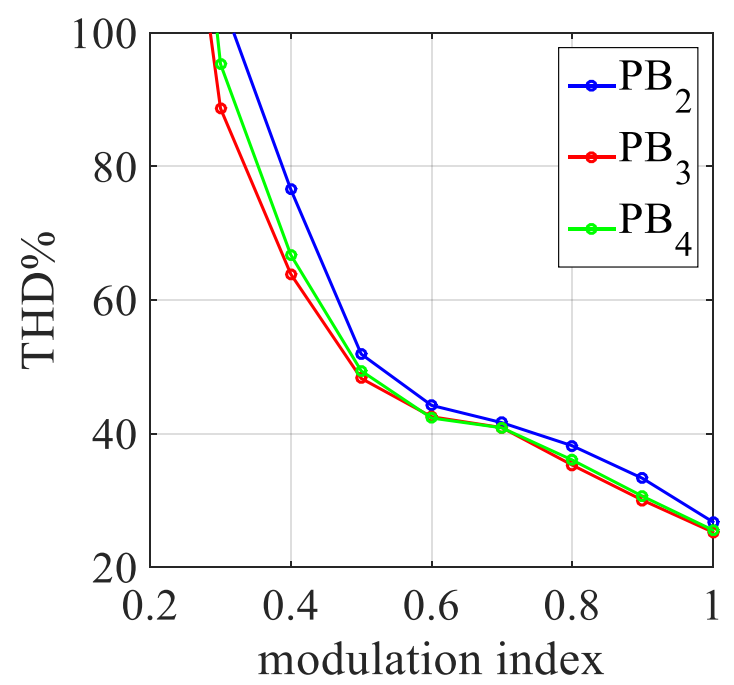

(b)

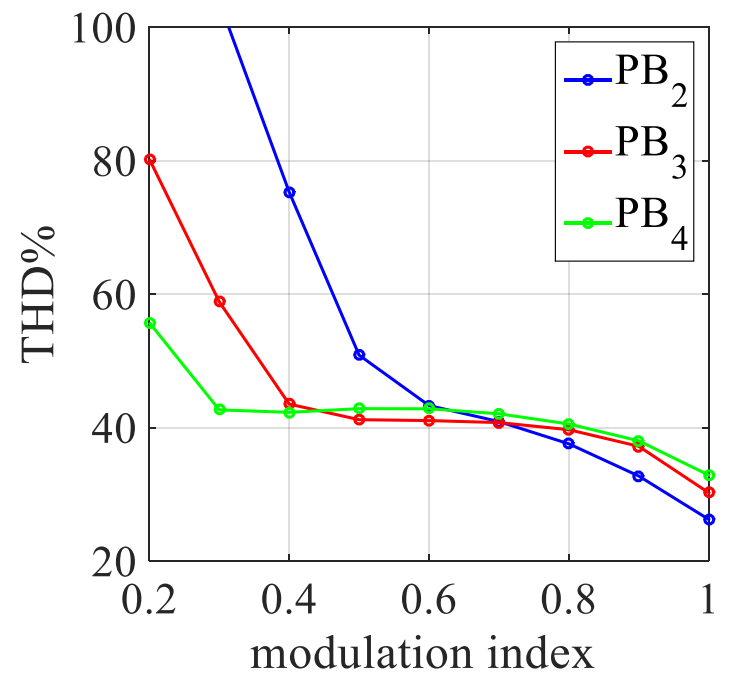

(d)

Figure 12. THD\% comparison between the PB2, PB3, and PB4 for each carrier signal: (a) PD, (b) POD, (c) APOD, and (d) PS.

This boost effect on the fundamental amplitude, due to the lower value of the intersection points, explains the lower values of the THD\% obtained from Equation (1). Thus, by adopting the B-Spline functions as carrier signals, the five-level voltage waveform appears for lower values of $\mathrm{M}$ with respect to the triangular carrier signal. In fact, the modulation techniques with $P B_{3}$ employs five-levels in the output phase voltage from $\mathrm{M}=0.37$, whereas the modulation techniques with $P B_{4}$ as carrier signal employ the five levels from $\mathrm{M}=0.26$.

Figures 14 and 15 show the voltage trends of $P B_{3}$ with $\mathrm{M}=0.4$ and $P B_{4}$ with $\mathrm{M}=0.3$. As previously mentioned, the comparison between these two figures demonstrates the so-called "boost effect" introduced by the B-Spline function. 


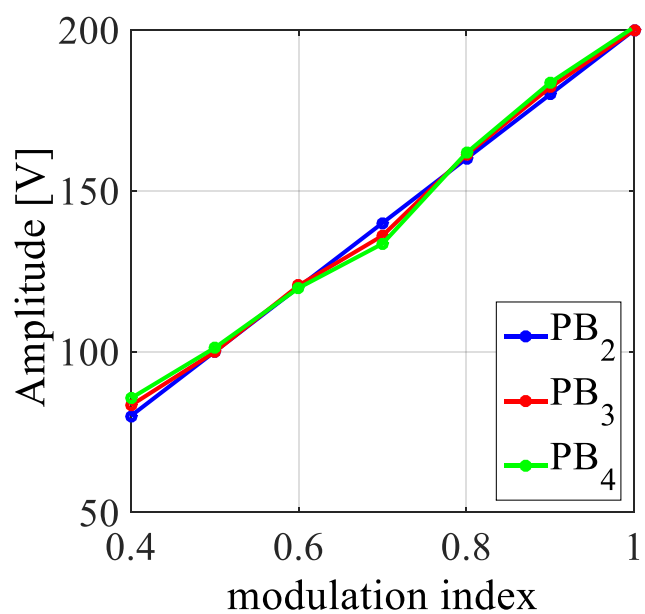

(a)

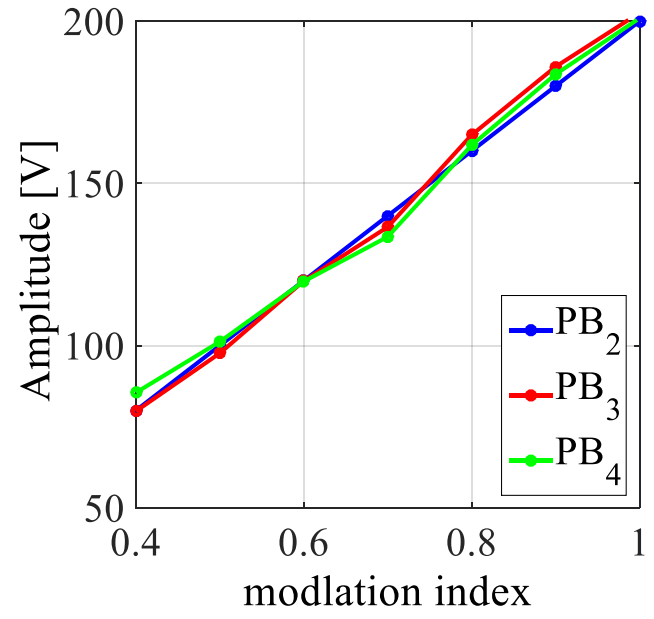

(c)

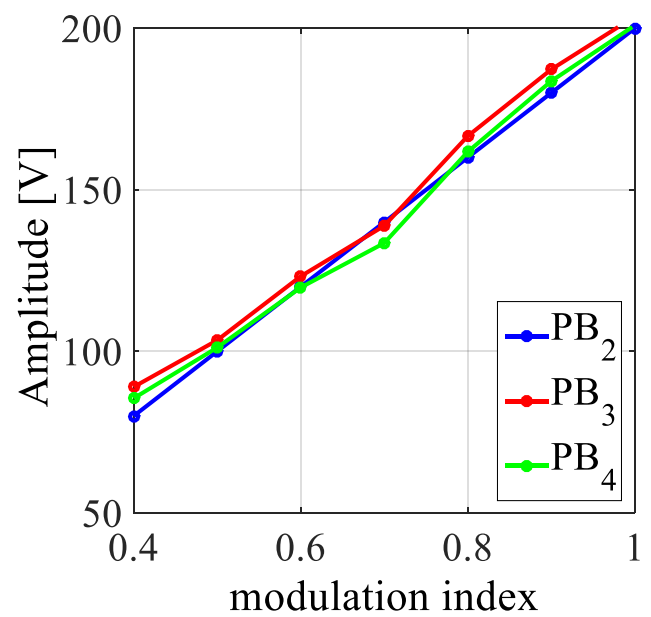

(b)

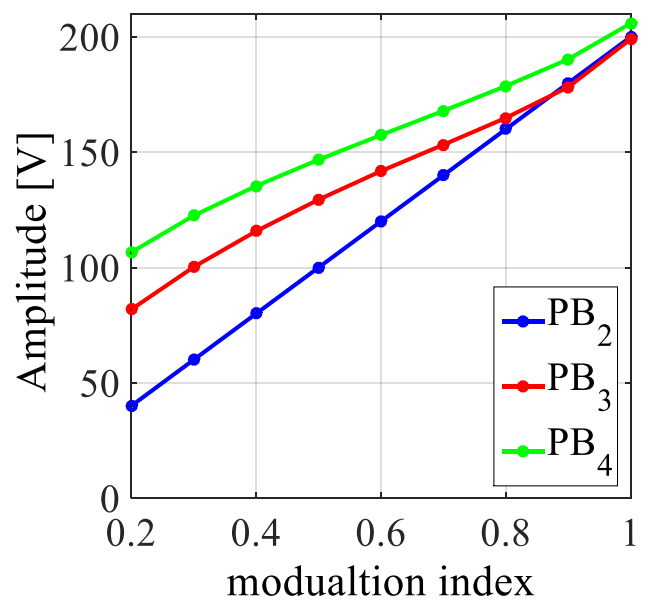

(d)

Figure 13. Fundamental amplitude comparison between the PB2, PB3, and PB4 for each carrier signal: (a) PD, (b) POD, (c) APOD, and (d) PS.

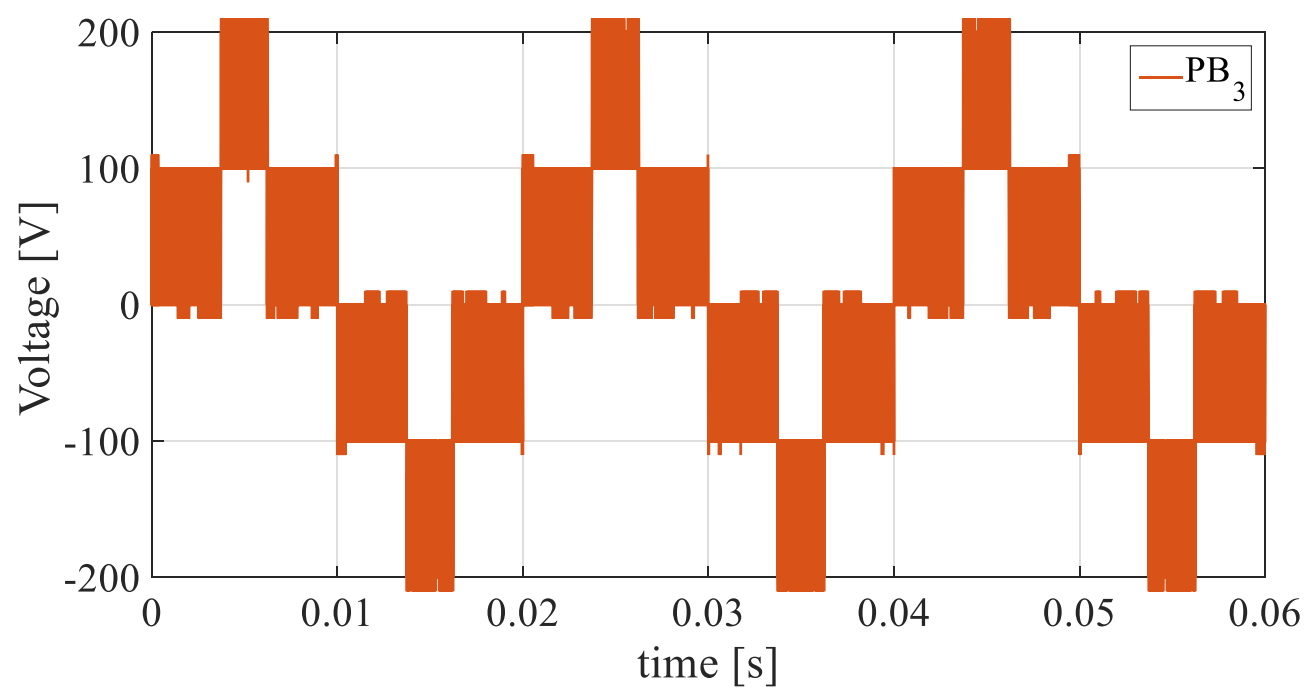

Figure 14. Voltage trend with $\mathrm{PB} 3$ as carrier signal and $\mathrm{M}=0.4$; the five-level voltage waveform appears for lower values of $\mathrm{M}$ with respect to the triangular carrier signal. 


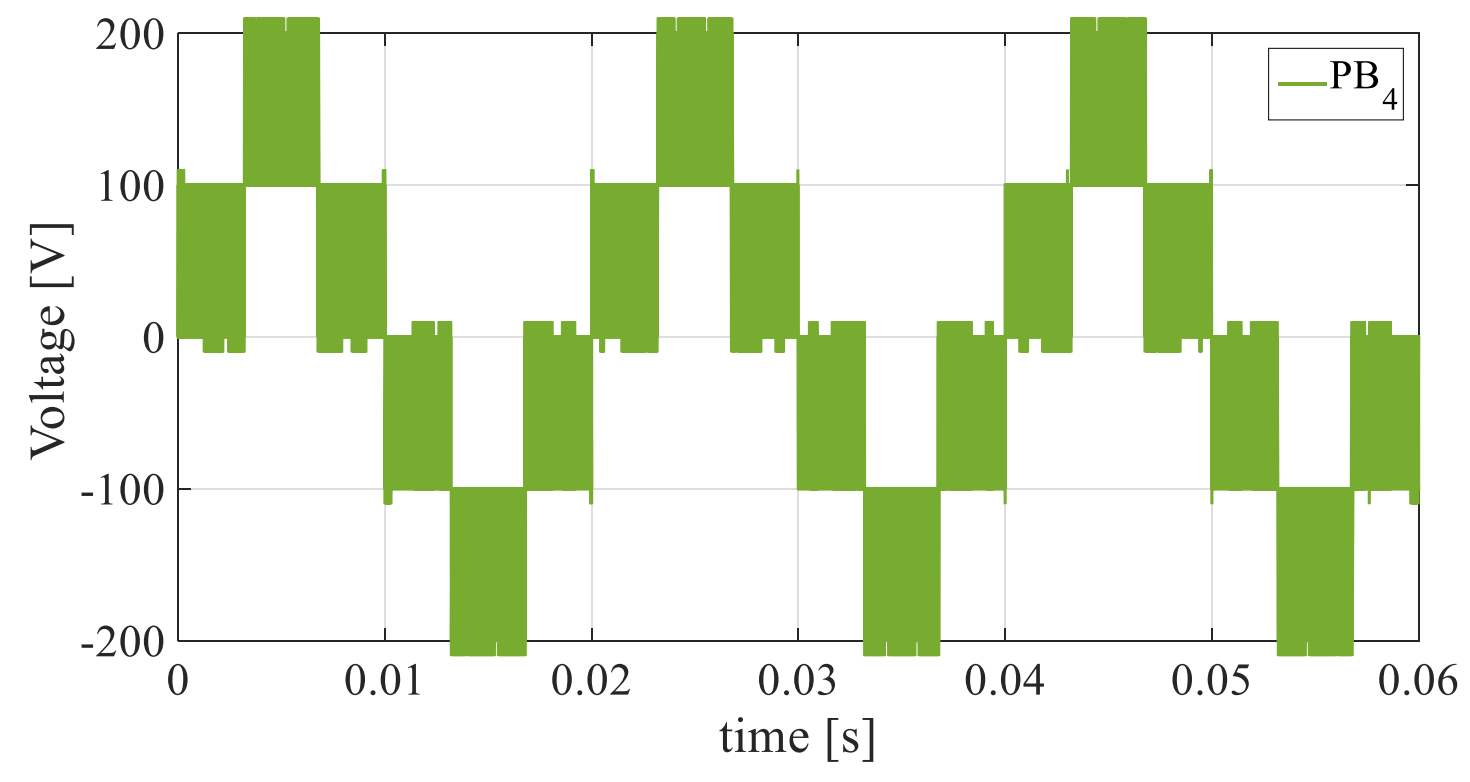

Figure 15. Voltage trend with PB4 as carrier signal and $M=0.3$, the five-level voltage waveform appears for lower values of $\mathrm{M}$ with respect to the triangular carrier signal.

Furthermore, Figure 16 shows the comparison between the THD\% values, obtained with the PS technique and $P B_{2}, P B_{3}$, and $P B_{4}$ as carrier signals, as function of the fundamental amplitude. Generally, it should be noted that, for an equal value of the fundamental amplitude, the lowest THD\% is detected with PB2, except for the range $[120 \mathrm{~V} 140 \mathrm{~V}]$ of the fundamental amplitude, in which similar values of THD\% are detected.

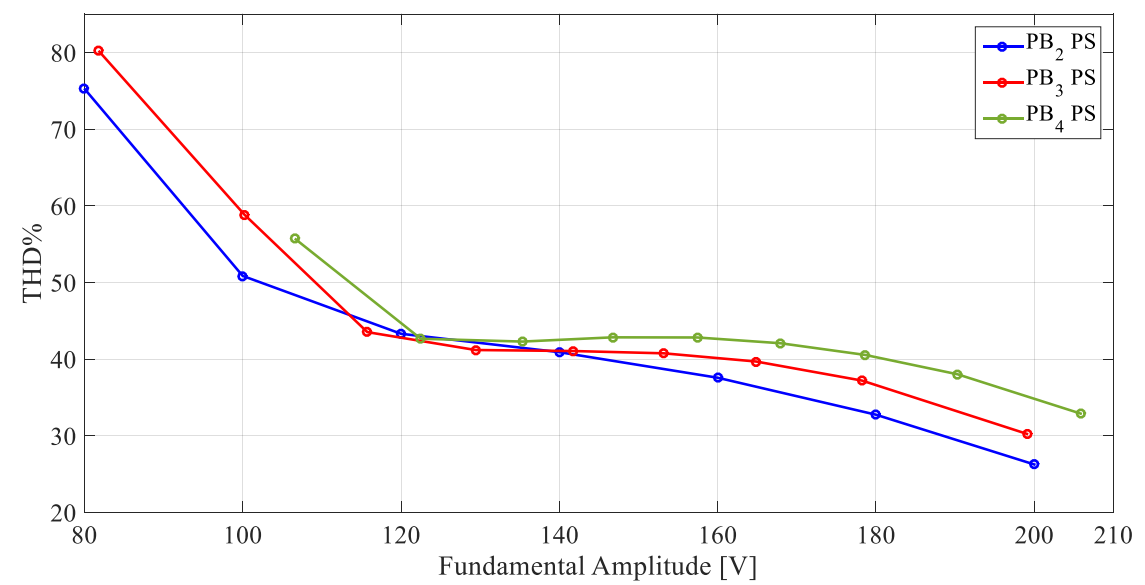

Figure 16. Comparison of THD\% versus fundamental amplitude among PB2, PB3, and PB4 for PS.

\subsection{Three-Phase Multilevel Inverters}

The comparison of both the THD\% and the fundamental amplitude of the line voltages as function of $\mathrm{M}$ for the $S P B_{2}, S P B_{3}$, and $S P B_{4}$ modulation techniques with sinusoidal reference are plotted in Figure 17. It can be noticed that the SPB4 allows the obtainment of lower THD \% values for modulation indexes less than 0.4 and higher fundamental amplitude values in the same range. For $\mathrm{M}$ in the range between 0.6 and 1, the traditional SPWM technique presents lower values of the THD\%, whereas in the over modulation region the THD\% presents similar values between all the techniques taken into account. 


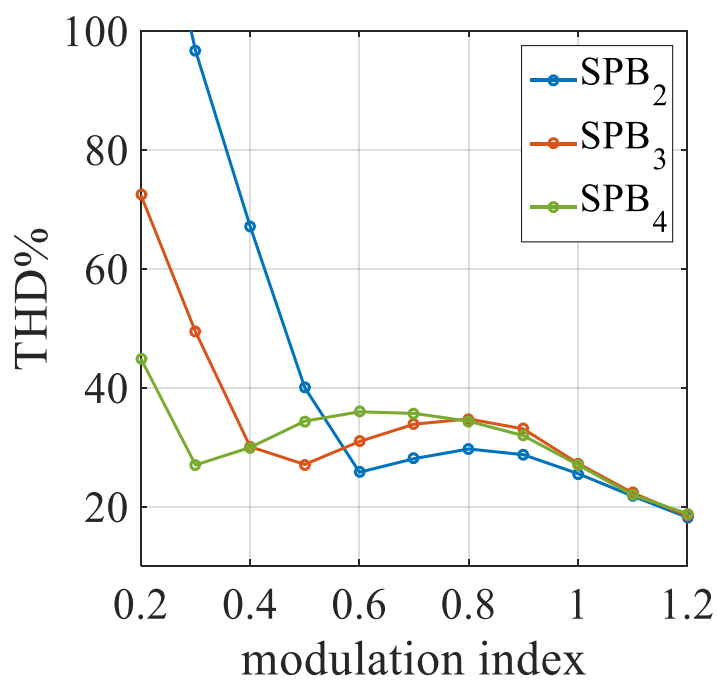

(a)

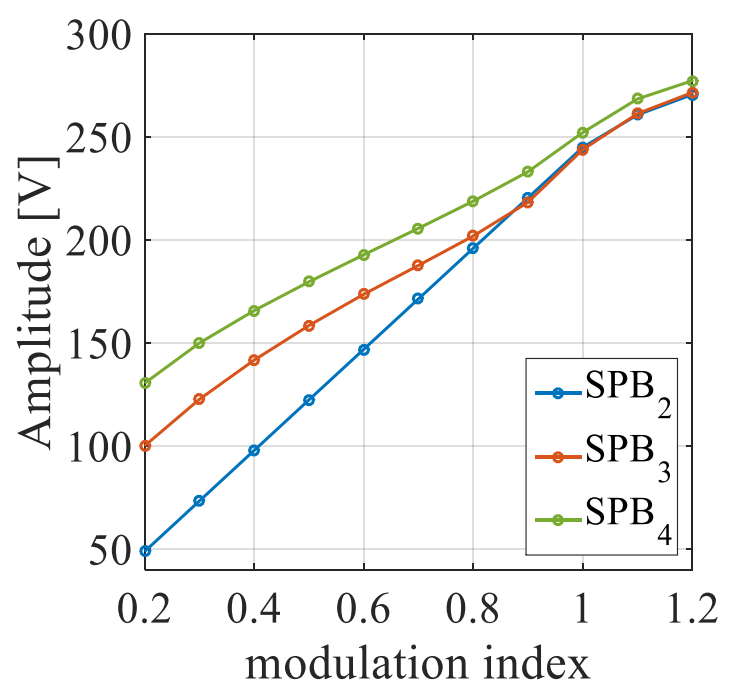

(b)

Figure 17. Comparison between the simulation results obtained with the modulation schemes $S P B_{2}$, $S P B_{3}$, and $S P B_{4}$ of: (a) THD\% and (b) peak values of fundamental amplitude of the line voltage.

Similar results in terms of THD\% values and fundamental line voltage amplitude are obtained for the SFO and THI modulation techniques, as shown in Figures 18 and 19. More in detail, lower values of THD $\%$ are obtained with traditional triangular carrier signal $\left(P B_{2}\right)$ for M between 0.6 to 1.2 , whereas the fundamental amplitude presents a boost effect for $\mathrm{M}$ in the ranges between the values $0.2-1$ and $0.2-0.9$ for $P B_{4}$ and $P B_{3}$, respectively. Similar values of the modulation techniques are detected in the over modulation region.

In order to determine the benefits provided by the THI and SFO reference signals with respect to the sinusoidal one, the THD\% and fundamental amplitude trends have been compared with $P B_{3}$ and $P B_{4}$ as carrier signals, as shown in Figures 20 and 21, respectively. In both cases, lower values of the $\mathrm{THD} \%$ are obtained with the sinusoidal reference signal, which is, therefore, the best solution in terms of reference signal.

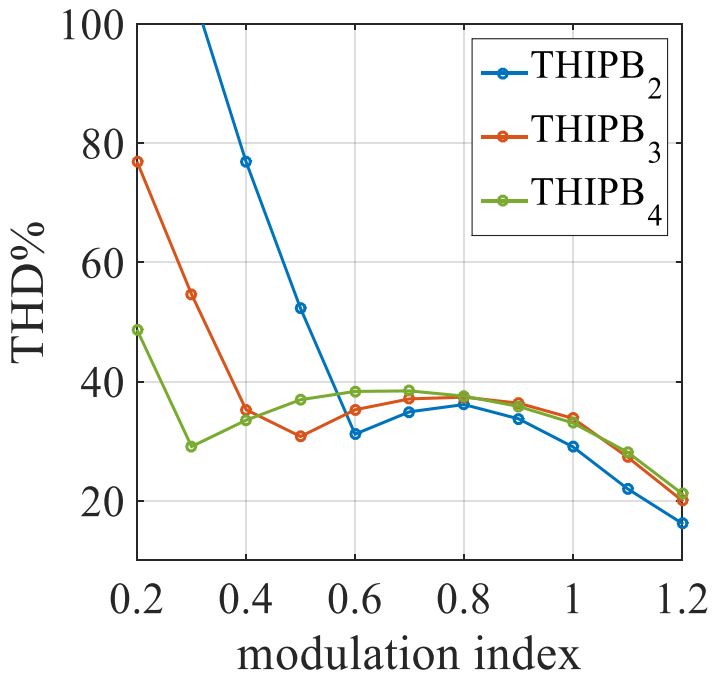

(a)

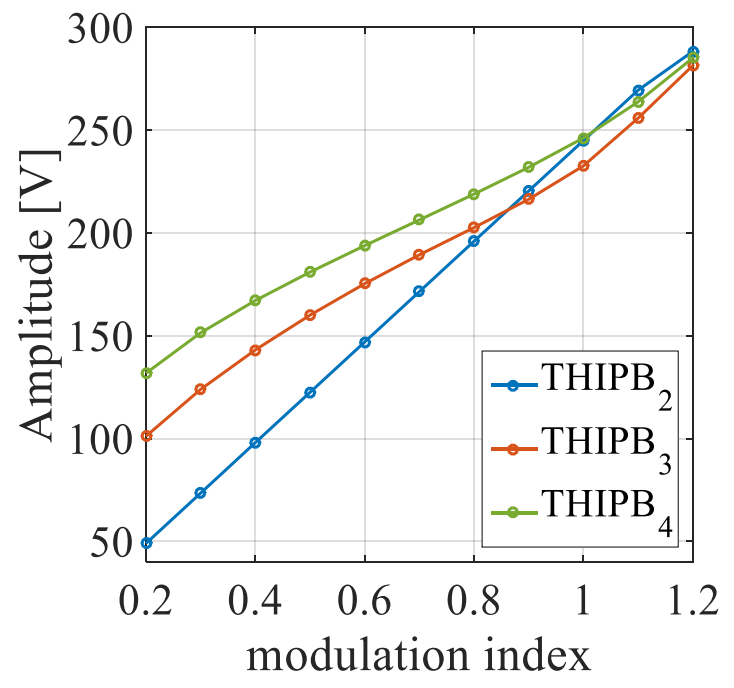

(b)

Figure 18. Comparison between the simulation results obtained with the modulation schemes $T H I P B_{2}$, $\mathrm{THIPB}_{3}$, and $\mathrm{THIPB}_{4}$ of: (a) THD\% and (b) peak values of fundamental amplitude of the line voltage. 


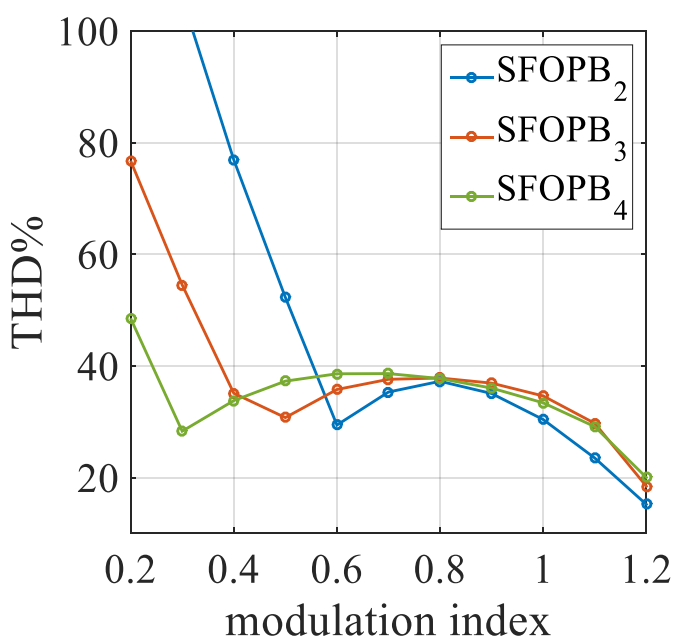

(a)

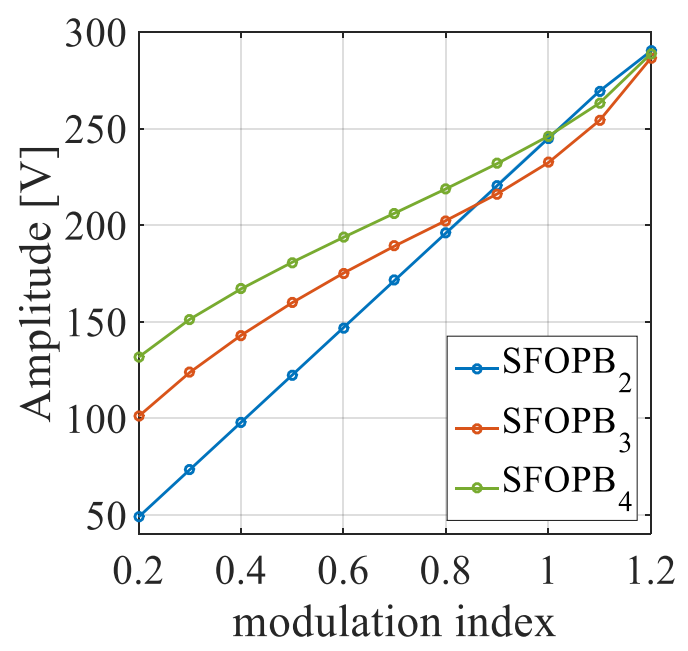

(b)

Figure 19. Comparison between the simulation results obtained with the modulation schemes $S F O P B_{2}$, $S F O P B_{3}$, and $S F O P B_{4}$ of: (a) THD\% and (b) peak values of fundamental amplitude of the line voltage.

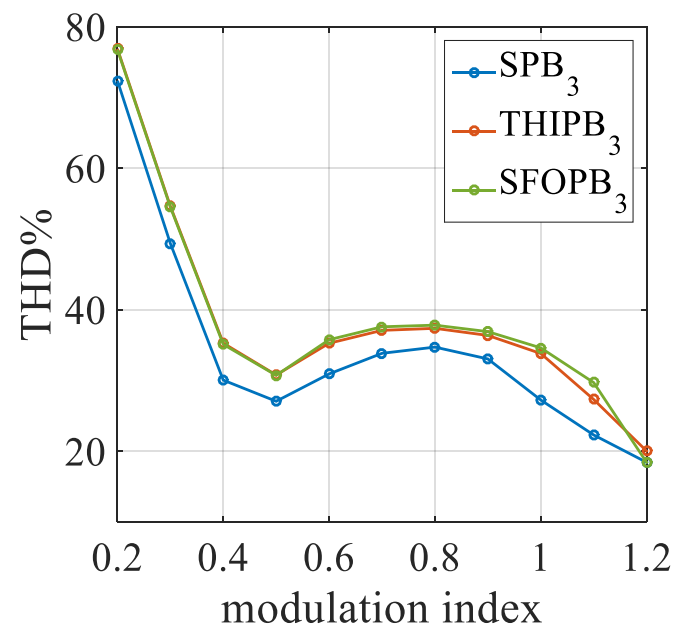

(a)

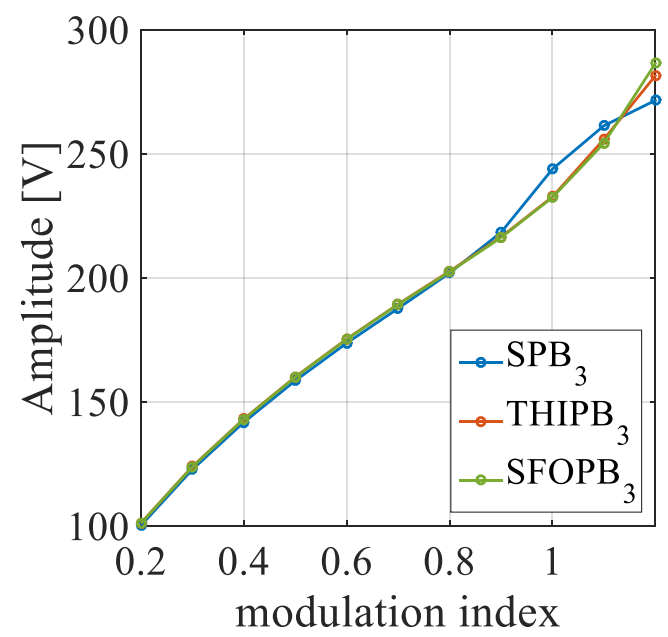

(b)

Figure 20. Comparison between the THD\% and fundamental amplitude of the line voltage with sinusoidal, THI, and SFO as reference signals and with $\mathrm{PB}_{3}$ as the carrier signal: (a) behavior of THD\%; (b) amplitude of fundamental.

As well as for the single-phase case, it is interesting to compare the THD\% values as a function of the fundamental amplitude, as shown in Figure 22, highlighting the fact that, for low values of the fundamental amplitude, the lowest THD\% values are obtained with $S P B_{2}$, except for values of fundamental amplitude around $220 \mathrm{~V}$, where similar values of $T H D \%$ between $S P B_{2}, S P B_{3}$, and $S P B_{4}$ are detected.

In order to perform a detailed comparison in terms of harmonic content, the Fast Fourier Transform (FFT) is applied to the output voltage of the inverter with the parameters reported in Table 2 (which summarizes the values of $\mathrm{M}$ and THD\% corresponding to $220 \mathrm{~V}$ of the fundamental amplitude for $P B_{2}$, $P B_{3}$, and $P B_{4}$ ), obtaining the results shown in Figure 23, which depicts the comparison of the harmonic spectra among the $S P B_{2}$ (blue bars), $S P B_{3}$ (red bars), and $S P B_{4}$ (green bars).

The harmonic spectra are comparable throughout the proposed modulation techniques. More in detail, at around four-times of the switching frequency, $S P B_{3}$ and $S P B_{4}$ present a pair of predominant side-band harmonics and other components, whose overall contribution is higher with respect to $S P B_{2}$. Moreover, at eight-times of the switching frequency, a relevant reduction is detected for the $S P B_{3}$ and $S P B_{4}$ components if compared with the $S P B_{2}$ harmonic components. Nevertheless, low-order 
harmonic components are detected in the harmonic spectra of both $S P B_{3}$ and $S P B_{4}$. However, the output line voltages from the inverter, corresponding to the supply voltages of a three-phase motor in case of electrical drive applications, are not affected by the low-order harmonics that are multiple of three.

Figure 24 shows the comparison between the fifth (a), seventh (b), 11th, (c) and 13th (d) order harmonics as function of $\mathrm{M}$, obtained with $S P B_{2}$ (blue bars), $S P B_{3}$ (red bars), and $S P B_{4}$ (green bars). As previously mentioned, low-order harmonics can be observed for each values of the modulation index.

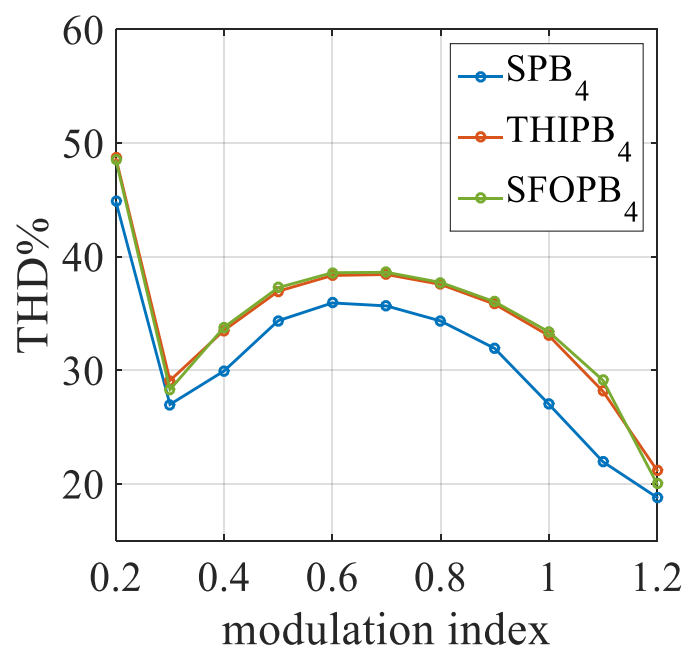

(a)

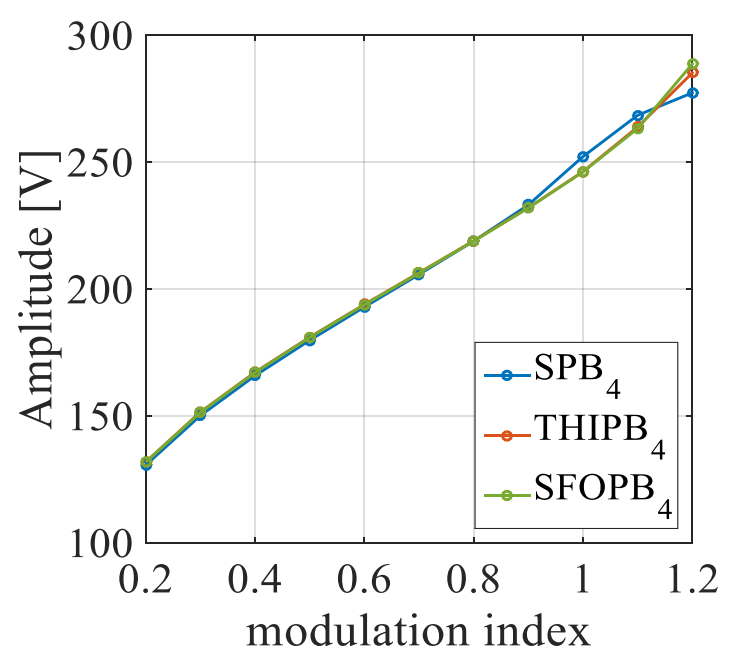

(b)

Figure 21. Comparison between the THD\% and fundamental amplitude of the line voltage with sinusoidal, THI, and SFO as reference signals and with $\mathrm{PB}_{4}$ as carrier signal: (a) behavior of $\mathrm{THD} \%$; (b) amplitude of fundamental.

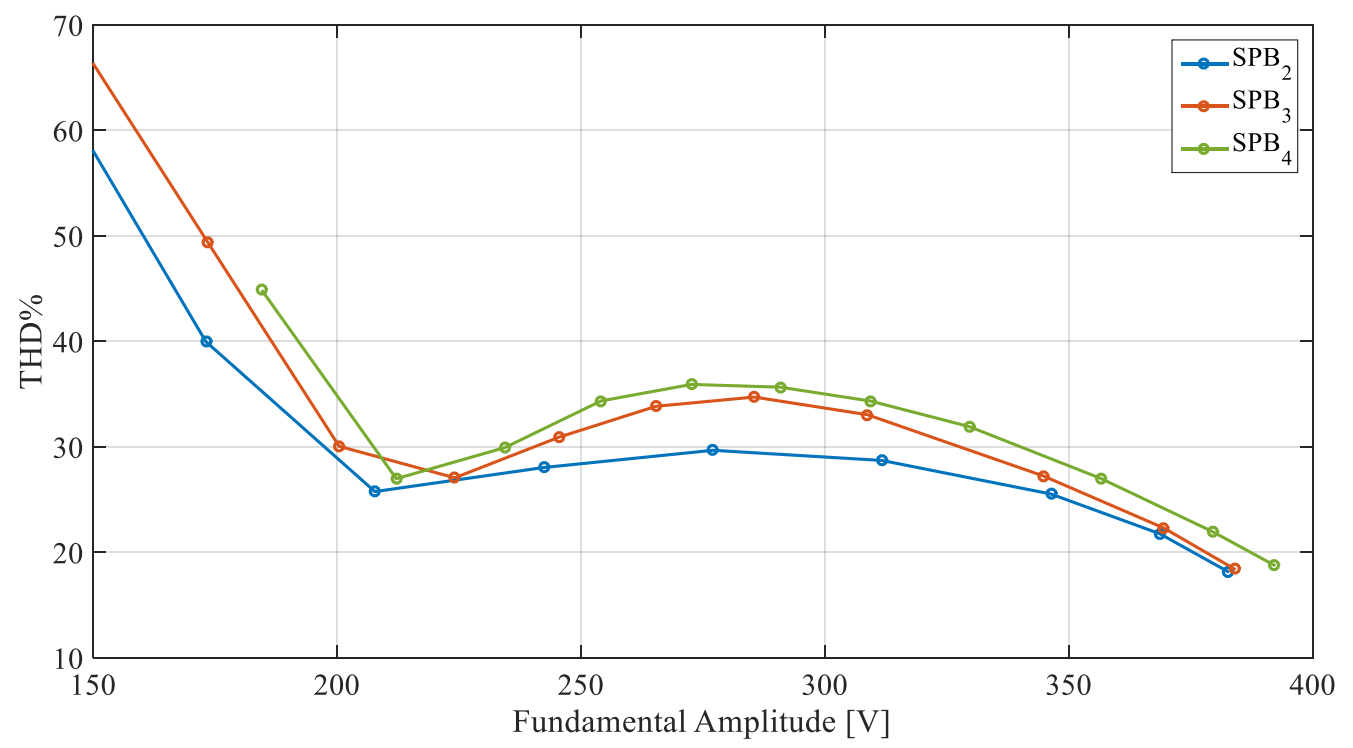

Figure 22. Comparison between the THD\% values as function of the fundamental amplitude among $S P B_{2}, S P B_{3}$, and $S P B_{4}$.

Table 2. Simulation parameters.

\begin{tabular}{cccc}
\hline Quantity & $S P B_{2}$ & $S P B_{3}$ & $S P B_{4}$ \\
\hline Modulation index, M & 0.63 & 0.5 & 0.3 \\
Fundamental Amplitude (peak value) & $219 \mathrm{~V}$ & $224 \mathrm{~V}$ & $214 \mathrm{~V}$ \\
THD $\%$ & $26.6 \%$ & $27.1 \%$ & $27 \%$ \\
\hline
\end{tabular}




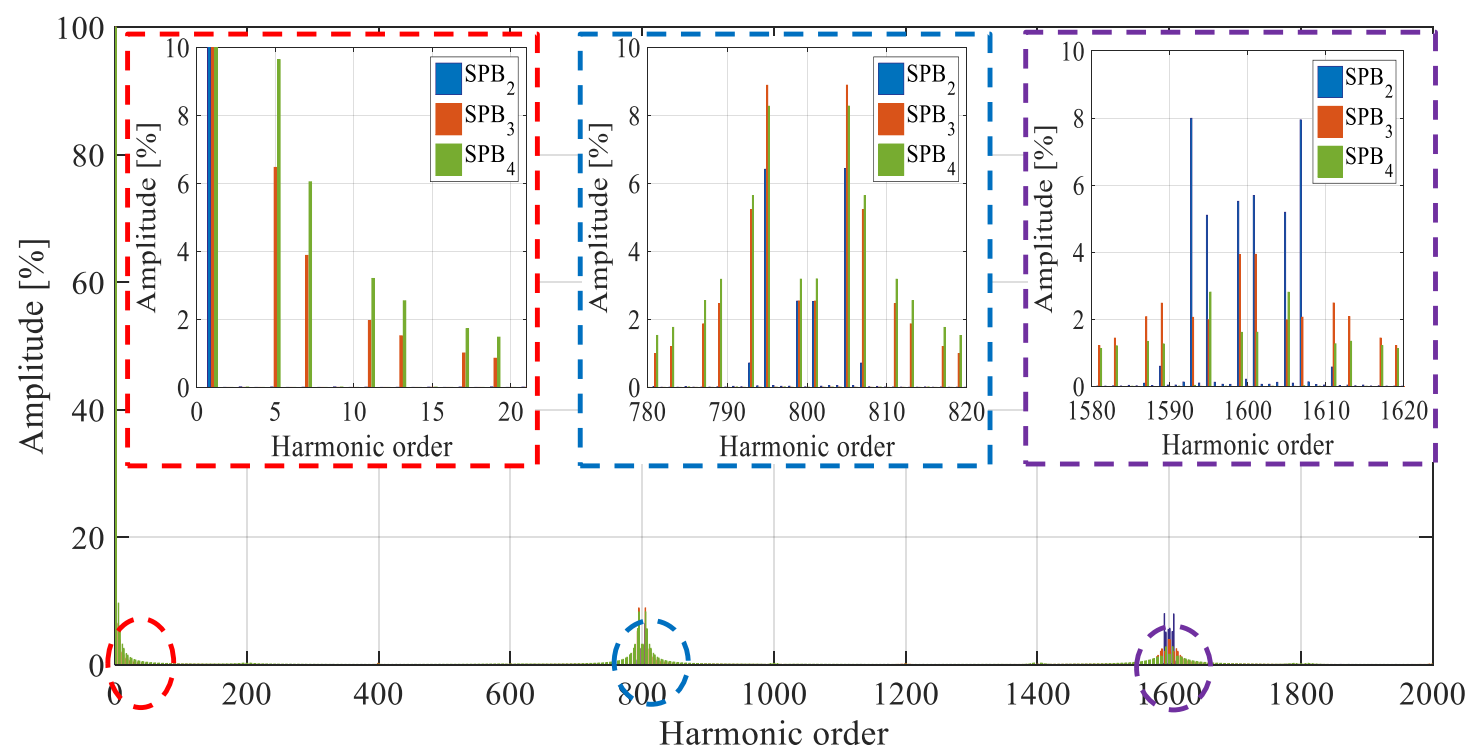

Figure 23. Comparison between the harmonic spectra referred to the fundamental amplitude of the line voltage for $S P B_{2}$ (blue bars), $S P B_{3}$ (red bars), and $S P B_{4}$ (green bars).

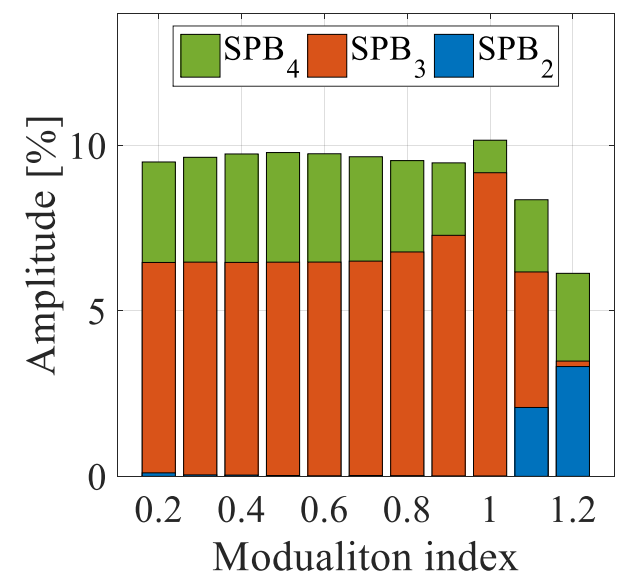

(a)

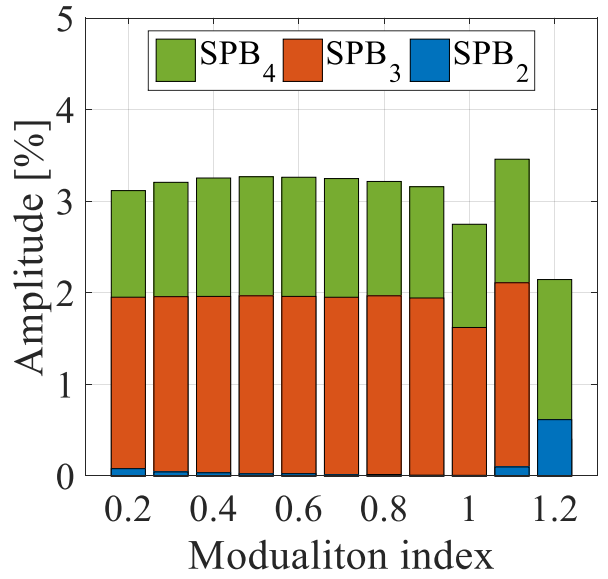

(c)

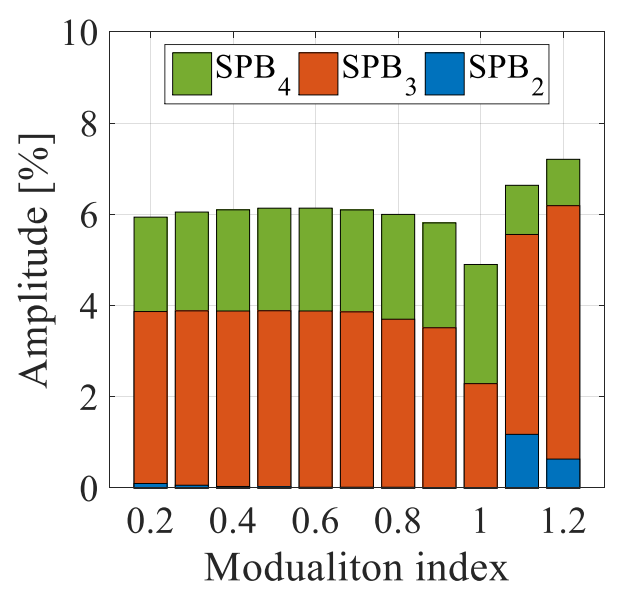

(b)

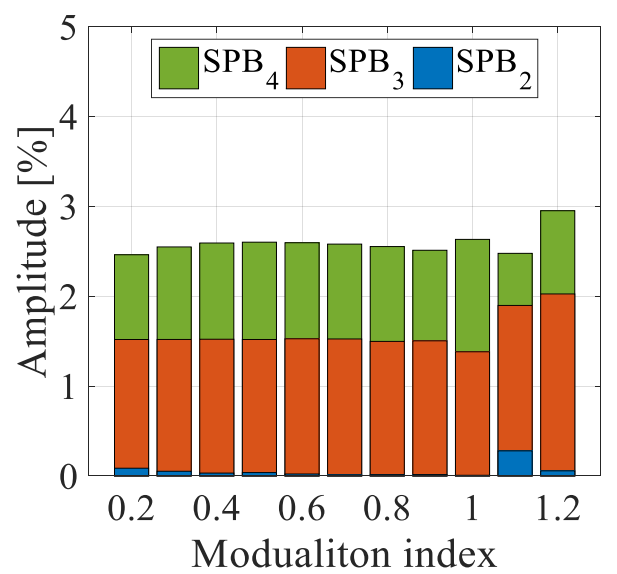

(d)

Figure 24. Comparison between the low order harmonics as function of M: (a) fifth order (b) seventh order (c) 11th order, and (d) 13th order harmonics. 
In conclusion, the simulation results have demonstrated that the highest values of THD $\%$ have been obtained for modulation techniques with $P B_{3}$ and $P B_{4}$ as carrier signals, detecting low order harmonic components in the harmonic spectra.

\section{Test Bench Equipment and FPGA Algorithm Design}

This Section provides a brief description of the test bench assembled in order to carry out the experimental results reported in Section 5. Figure 25 shows a photograph of the test bench, which is mainly composed by the following elements:

$>$ A five-level three-phase power MOSFET-based Cascaded H-Bridge;

$>$ Six independent DC sources, each one with a rated voltage equal to $12 \mathrm{~V}$;

$>$ A control board, based on a prototype of Field Programmable Gate Array (FPGA) (ALTERA, DigiPowers.r.l, model Cyclone III);

$>$ A scope (LeCroyWaveRunner 6Zi Teledyne), which is adopted in order to monitor and acquire in real-time the waveforms of voltage and current;

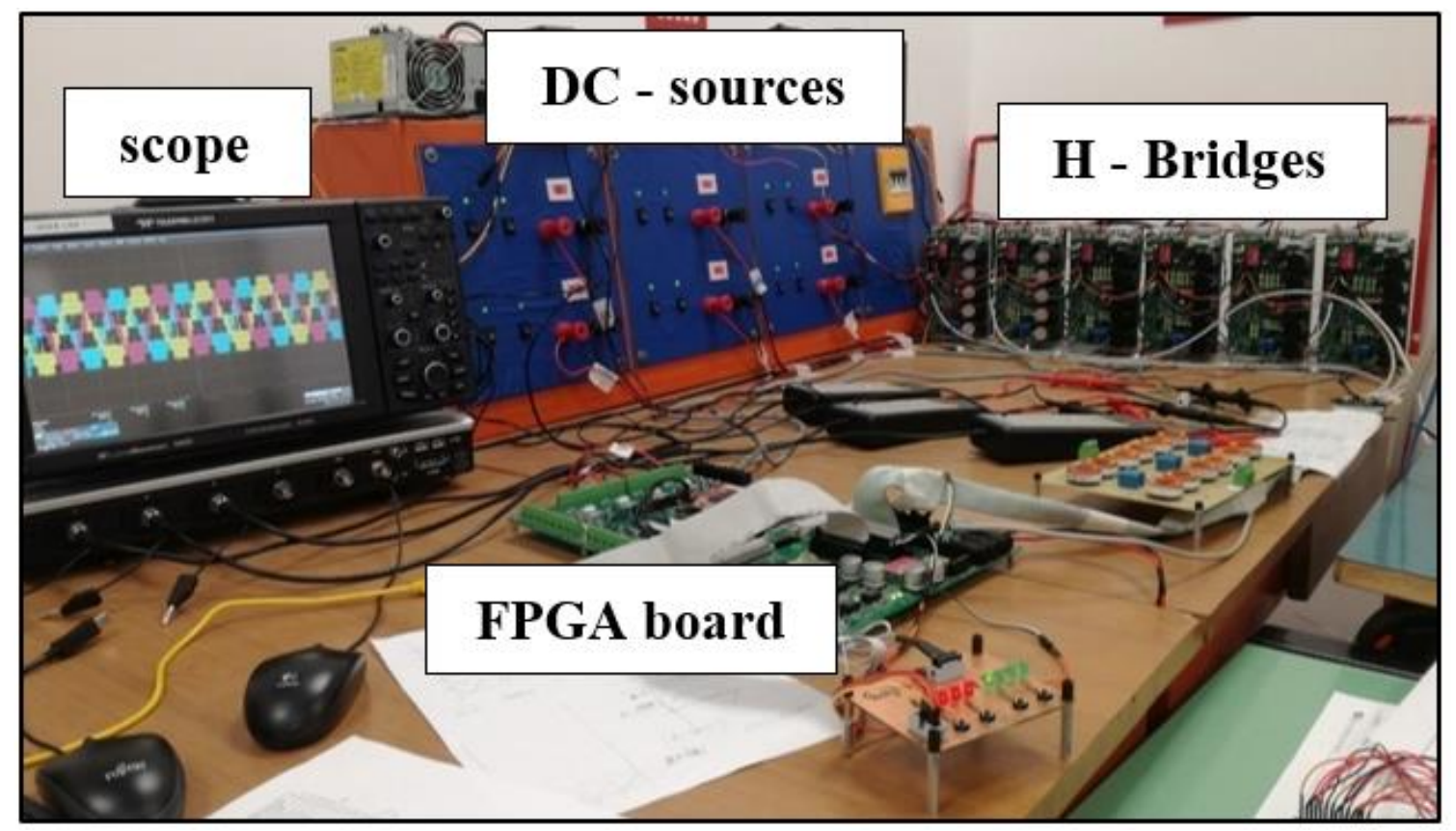

Figure 25. Photograph of the test bench.

Figure 26 shows the block diagram of the control algorithm implemented in the QuartusII ${ }^{\circledR}$ (Intel Corporationcity, Santa Clara, CA, USA) environment. This scheme is mainly composed by a digital PLL (Phase Locked Loop), a carrier/reference signals generator, a modulation index block, a comparator and a dead-time generator.

The digital PLL allows the generation of the clock signals for each sub-circuit of the system from an external clock signal at a frequency equal to $10 \mathrm{MHz}$. The modulation index and the reference signals blocks generate the three-phase sinusoidal reference with a fixed amplitude. The sinusoidal reference signals have been sampled with a sample number equal to 200. Thus, these blocks need a clock reference with a frequency equal to $10 \mathrm{kHz}$ in order to obtain a fundamental frequency of $50 \mathrm{~Hz}$.

The generation of $P B_{3}$ and $P B_{4}$ is achieved by means of the carrier signal block, whereas the comparator circuit and the dead-time generator blocks allow generating the gate signals and the dead time equal to $400 \mathrm{~ns}$ to control the converter through a comparison between the reference signal and carrier signal with a frequency at $40 \mathrm{MHz}$. 


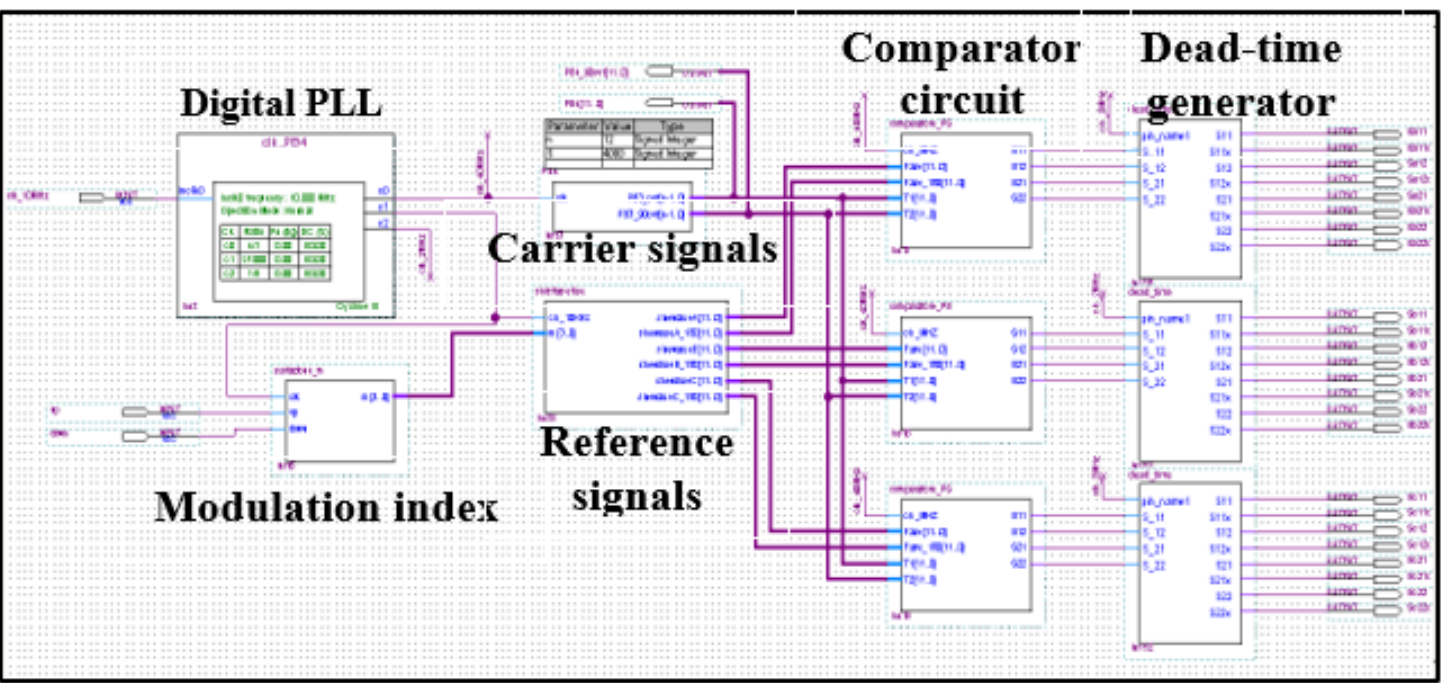

Figure 26. Block diagram of the control algorithm in the Quartus II environment.

\section{Experimental Results and Discussion}

The objective of this section is to validate the simulation results described in Section 4 through experimental tests. As mentioned in Section 4, the simulation results for the single-phase case has determined that the most suitable modulation scheme applied to multilevel inverters is the Sinusoidal Phase-Shifted. From this statement, a comparison between simulation and experimental results are reported only for the three-phase case with the SPS technique adopting $P B_{3}$ and $P B_{4}$, due to the fact that the single-phase cases are not considered of interest in the proposed work.

By means of the described test bench and control algorithm, the techniques proposed in Section 3 have been experimentally implemented and Figure $27 \mathrm{a}-\mathrm{f}$ shows the trend of the output line voltage with $\mathrm{M}$ ranging from 0.3 to 0.5 for $S P B_{3}$ and $S P B_{4}$. It appears evident that these experimental trends present the same behavior of those determined by means of the simulation analysis. In particular, by adopting $S P B_{4}$ as carrier signal, a five-level voltage for low values of the $\mathrm{M}$ is obtained. This phenomenon is due to the lower point of intersection between the carrier signals and it explains the boost effect on the fundamental amplitude. In order to compare the overall harmonic components, the voltage waveforms have been acquired for different values of the modulation index with the parameters reported in Table 3 .

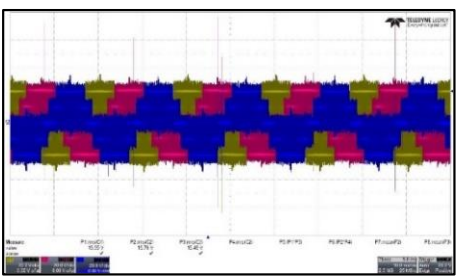

(a) $\mathrm{SPB}_{3}-\mathrm{M}=0.3$

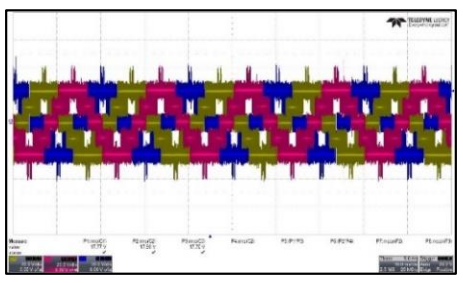

(d) $S P B_{4}-M=0.3$

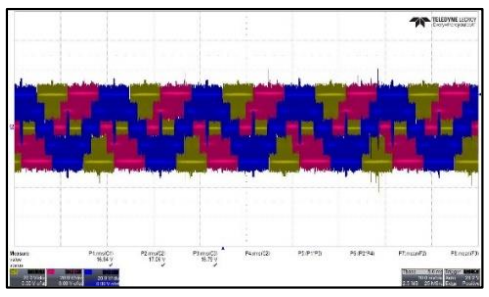

(b) $S P B_{3}-M=0.4$

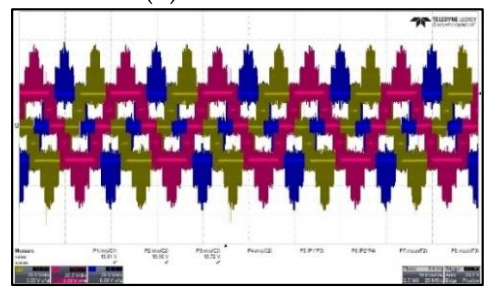

(e) $S P B_{4}-M=0.4$

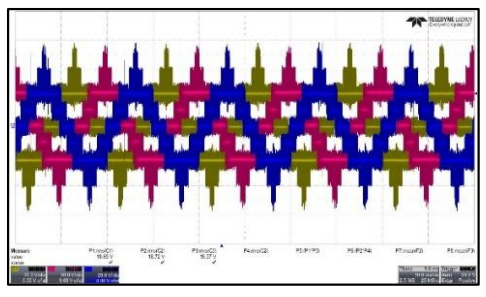

(c) $S P B_{3}-M=0.5$

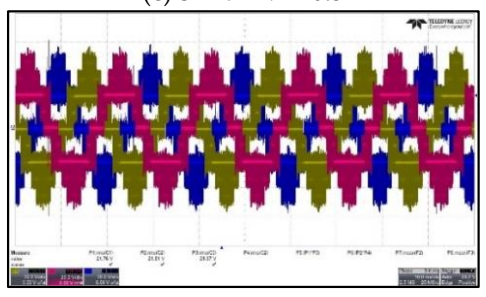

(f) $S P B_{4}-M=0.5$

Figure 27. Evolution of the line voltage trend for low modulation index values between SPB3 and SPB4. (a) $S P B_{3}$ and $\mathrm{M}=0.3$ realize a three level operation, (b) $S P B_{3}$ and $\mathrm{M}=0.4$ realize a three level operation,

(c) $S P B_{3}$ and $\mathrm{M}=0.5$ realize a five level operation, (d) $S P B_{4}$ and $\mathrm{M}=0.3$ realize a three level operation,

(e) $S P B_{4}$ and $\mathrm{M}=0.4$ realize a five level operation, (f) $S P B_{4}$ and $\mathrm{M}=0.5$ realize a three level operation. 
Table 3. Acquisition parameters.

\begin{tabular}{cc}
\hline Quantity & Value \\
\hline Sample frequency & $25 \mathrm{MHz}$ \\
Sample number & 500,000 \\
Acquisition time & $20 \mathrm{~ms}$ \\
\hline
\end{tabular}

Figure 28 shows the computed THD\% values of $S P B_{2}$ (blue curve), $S P B_{3}$ (yellow curve), and $S P B_{4}$ (green curve) of the phase voltage (Figure 28a) and line voltage (Figure 28b).

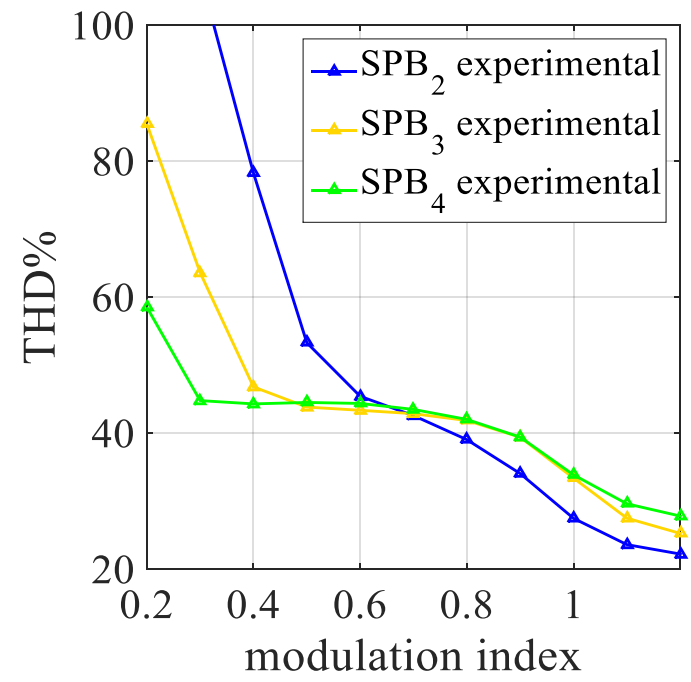

(a)

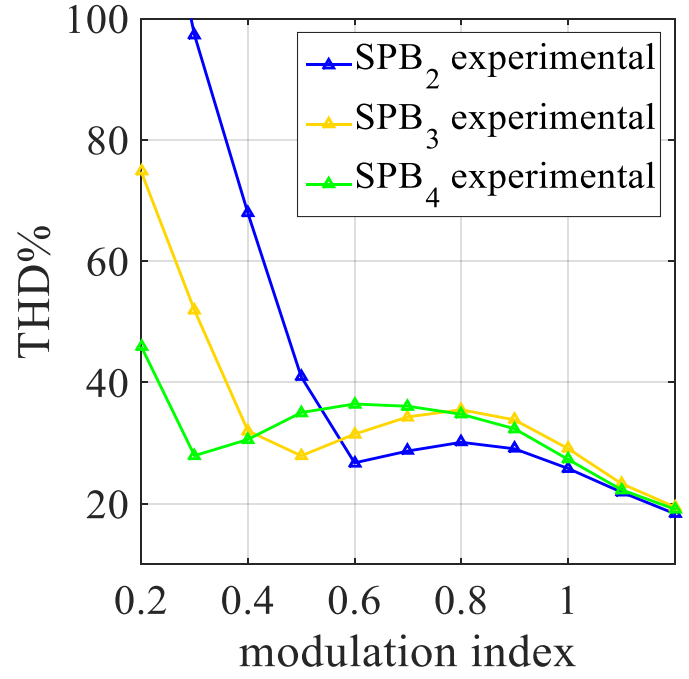

(b)

Figure 28. Comparison between the experimental $\mathrm{THD} \%$ obtained with $S P B_{2}, S P B_{3}$, and $S P B_{4}$ : (a) phase voltage and (b) line voltage.

Moreover, the comparison between the computed THD\% values confirm the results discussed in Section 4 . In particular, the lowest values of the THD\% are obtained with $P B_{2}$ as carrier signals and the boost effect is clearly displayed in the experimental fundamental amplitude trend, as shown in Figure 29.

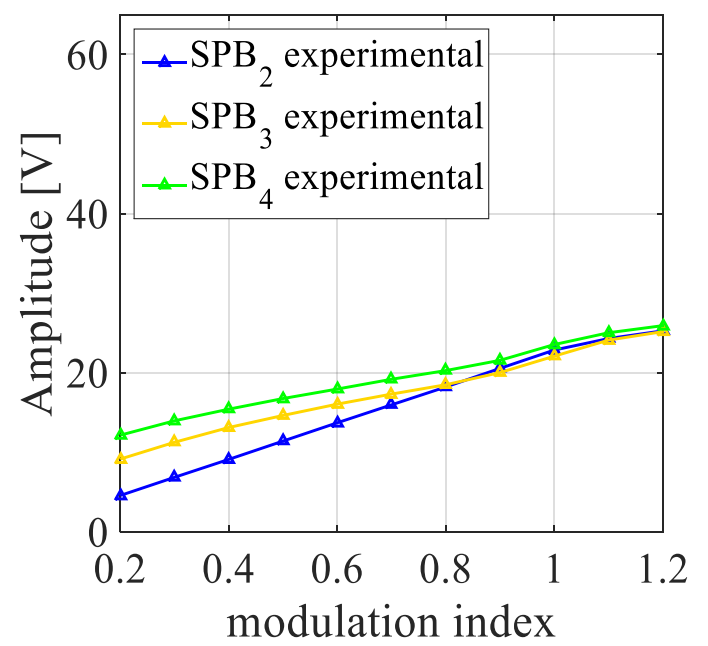

(a)

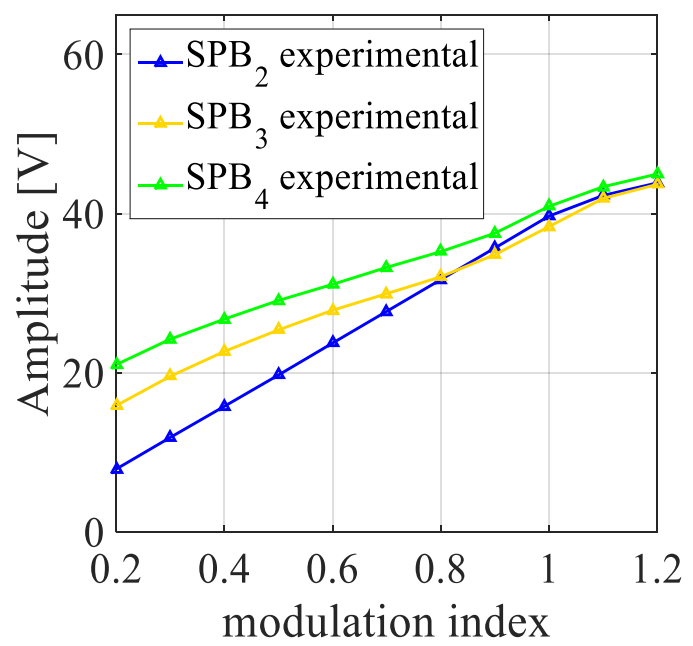

(b)

Figure 29. Comparison between the experimental fundamental amplitude with $S P B_{2}, S P B_{3}$, and $S P B_{4}$ : (a) phase voltage and (b) line voltage. 
In any case, as mentioned in Section 4, the output line voltages from the inverter, corresponding to the supply voltages of a three-phase motor in case of electrical drive applications, are not affected by the low-order harmonics that are multiple of three.

Finally, the comparability between the simulation and experimental results in terms of THD\% can be clearly visualized for $S P B_{2}, S P B_{3}$, and $S P B_{4}$ in Figure 30, Figure 31, and Figure 32, respectively.

Figure 33 shows the screenshot of the phase voltage for different values of the modulation index from 0.2 to 1.0 and low order harmonics spectra with $P B_{4}$ as carrier signals.

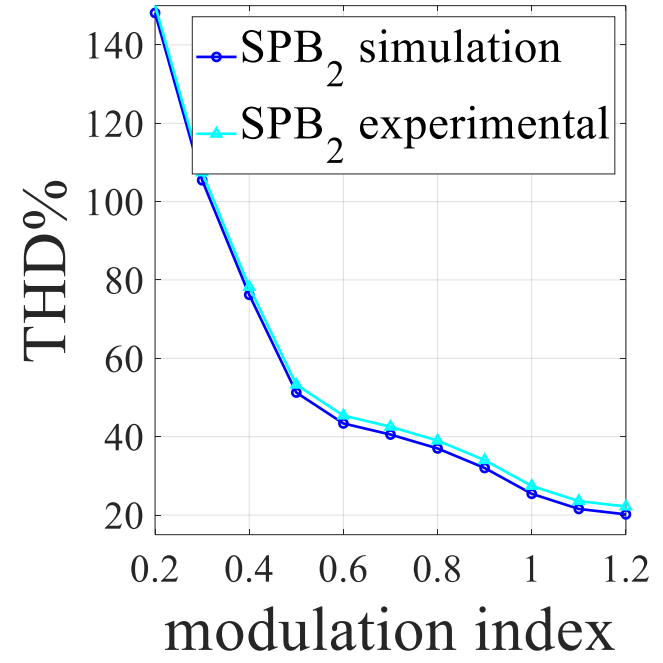

(a)

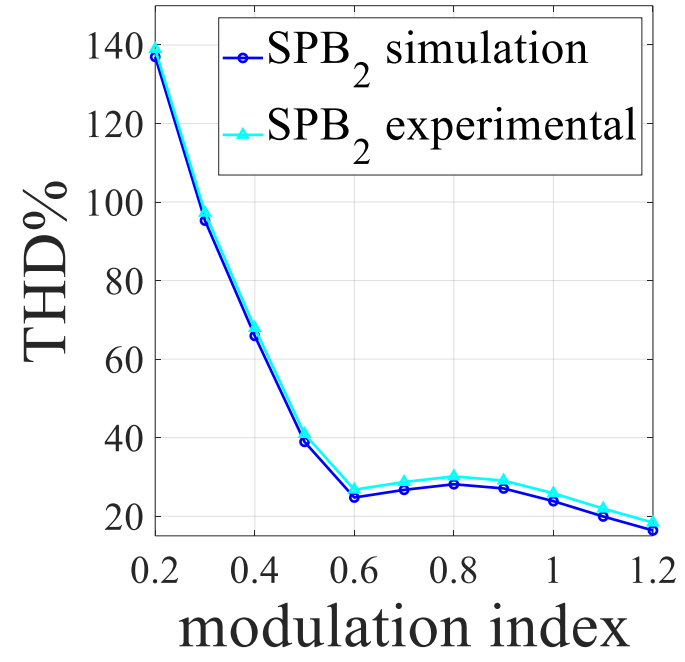

(b)

Figure 30. Comparison between the simulated and experimental $\mathrm{THD} \% P B_{2}$ as carrier signal: (a) phase voltage and (b) line voltage.

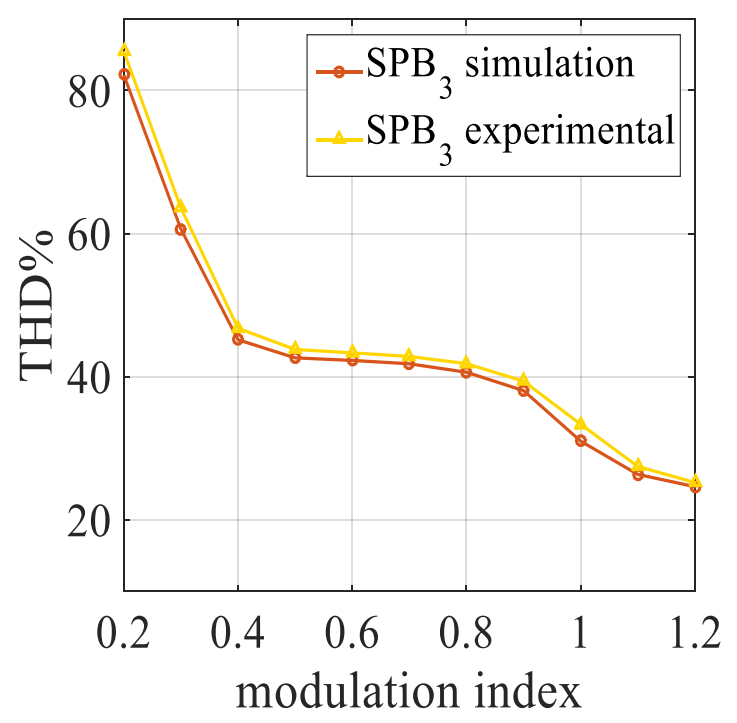

(a)

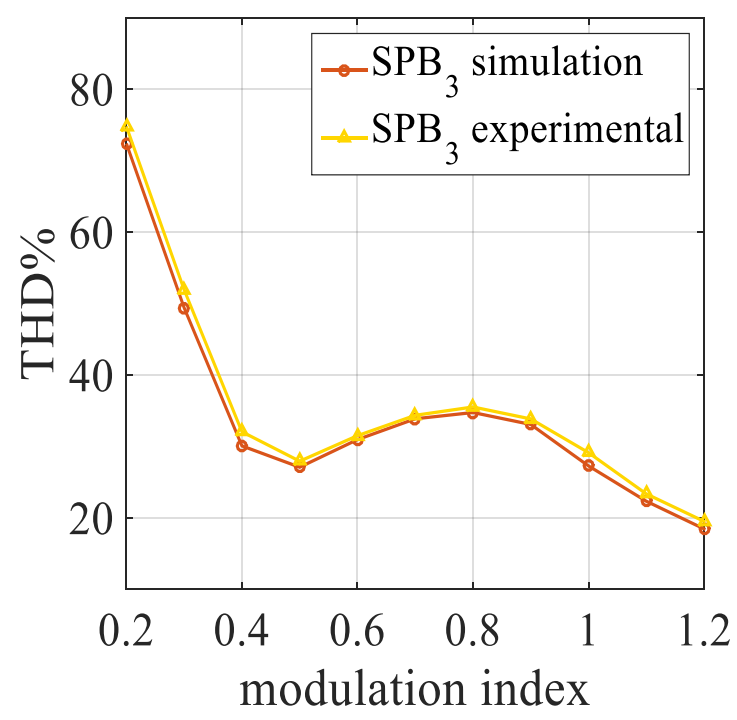

(b)

Figure 31. Comparison between the simulated and experimental $\mathrm{THD} \% P B_{3}$ as carrier signal: (a) phase voltage and (b) line voltage. 


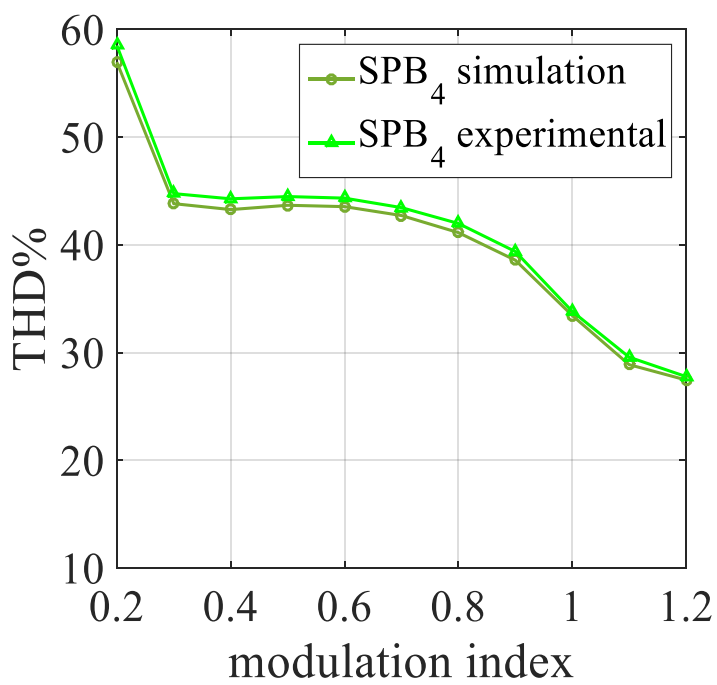

(a)

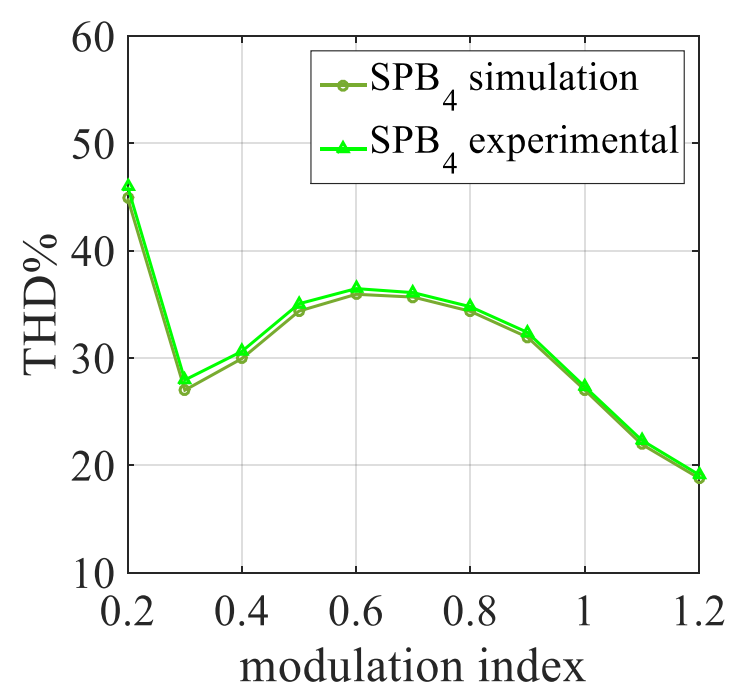

(b)

Figure 32. Comparison between the simulated and experimental THD $\% P B_{4}$ as carrier signal: (a) phase voltage and (b) line voltage.

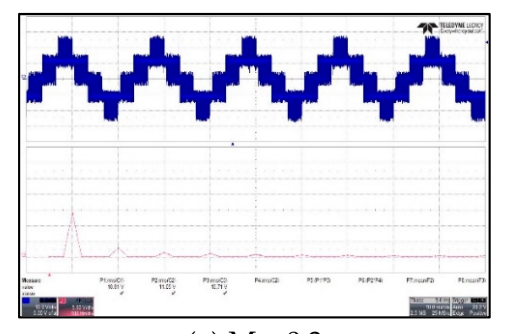

(a) $\mathrm{M}=0.3$

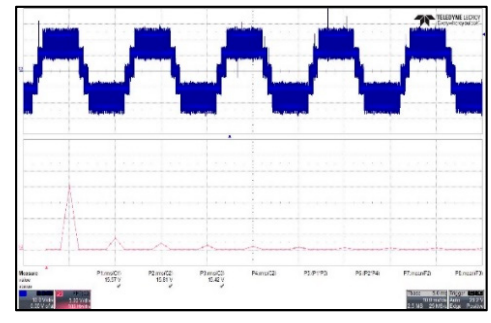

(d) $\mathrm{M}=0.8$

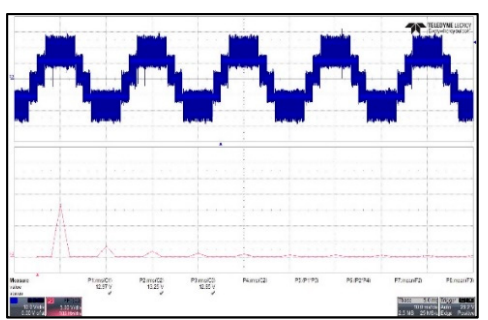

(b) $\mathrm{M}=0.5$

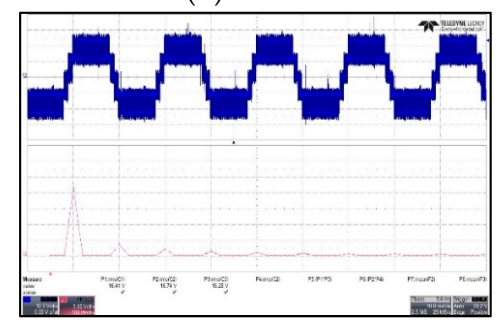

(e) $\mathrm{M}=0.9$

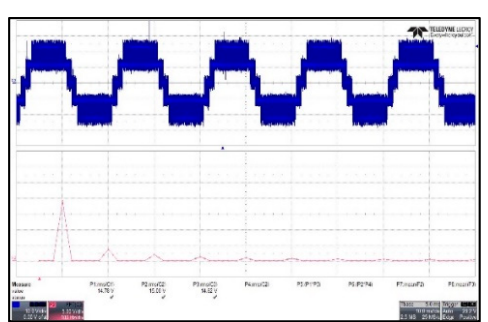

(c) $\mathrm{M}=0.7$

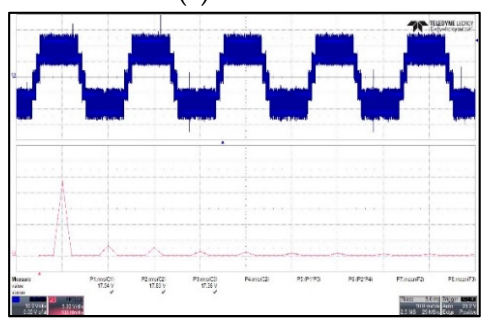

(f) $M=1$

Figure 33. Screenshot of the phase voltage and low order harmonics spectra with PB4 as carrier signals for modulation index from 0.3 to 1 (10 V/div and $100 \mathrm{~Hz} / \mathrm{div})$. (a) low value of fundamental due to the limited five level operation; (b) limited increase of fundamental; (c) appreciable increase of the fundamental; (d) considerable increase of fundamental; (e) good operation of the fundamental; (f) maximum value of the fundamental.

\section{Conclusions}

This paper has presented an experimental investigation on the adoption of innovative B-Splinebased modulation schemes applied to multilevel Voltage Source Inverters. The Simulation results carried out through the Matlab/Simulink environment are in accordance with the experimental tests, highlighting the fact that the B-Spline functions for multilevel inverters applied, for example, in the field of electrical drives, could bring benefits in terms of increasing the multilevel operation of the converter, but also drawbacks in terms of the presence of some low-order harmonic components in the spectra of the output voltages of the CHBMI.

Author Contributions: Conceptualization, G.S., F.V., and M.C.; methodology, R.M.; software, G.S.; validation, G.S.; writing—review and editing, F.P., V.C., G.S., F.V., and M.C.; supervision, G.A. and M.T. 
Funding: This research received no external funding. This work was financially supported by MIUR-Ministero dell'Istruzione dell'Università e della Ricerca (Italian Ministry of Education, University and Research) and by SDESLab (Sustainable Development and Energy Saving Laboratory) and LEAP (Laboratory of Electrical APplications) of the University of Palermo.

Conflicts of Interest: The authors declare no conflict of interest.

\section{References}

1. De Almeida, A.T.; Ferreira, F.J.T.E.; Quintino, A. Technical and economical considerations on super highefficiency three-phase motors. In Proceedings of the 48th IEEE Industrial \& Commercial Power Systems Conference, Louisville, KY, USA, 20-24 May 2012; pp. 1-13. [CrossRef]

2. Ferreira, F.J.T.E.; de Almeida, A.T. Reducing Energy Costs in Electric-Motor-Driven Systems: Savings Through Output Power Reduction and Energy Regeneration. IEEE Ind. Appl. Mag. 2018, 24, 84-97. [CrossRef]

3. De Almeida, P.; Fonseca, F.; Ferreira, F.; Guisse, J.; Blaise, E.; Clair, A.; Diop, A.; Previ, A.; Dominioni, M.; Di Pillo, S.; et al. Improving the Penetration of Energy Efficient Motors and Drives; Technical Report 4.1031/Z96-044; SAVE II Programme; Directorate General of Energy, European Commission: Brussels, Belgium, 2000. Available online: http://publica.fraunhofer.de/dokumente/n-6399.html (accessed on 20 November 2019).

4. Ferreira, F.; Baoming, G.; de Almeida, A.T. Reliability and operation of high-efficiency induction motors. In Proceedings of the 51st IEEE Industrial \& Commercial Power Systems Technical Conf. (I\&CPS'2015), Calgary, AB, Canada, 6-8 May 2015; pp. 1-13.

5. Caruso, M.; Di Tommaso, A.O.; Miceli, R.; Nevoloso, C.; Spataro, C.; Viola, F. Characterization of the parameters of interior permanent magnet synchronous motors for a loss model algorithm. Meas. J. Int. Meas.Confed. 2017, 106, 196-202. [CrossRef]

6. Kouro, S.; Malinowski, M.; Gopakumar, K.; Pou, L.; Franquello, L.G.; Wu, B.; Rodriguez, J.; Perez, M.A.; Leon, J.I. Recent Advances and Industrial Applications of Multilevel Converters. IEEE Trans. Ind. Electron. 2010, 57, 2553-2580. [CrossRef]

7. Rodriguez, J.; Franquelo, L.G.; Kouro, S.; Leon, J.I.; Portillo, C.; Prats, M.A.M.; Perez, M.A. Multilevel Converters: An Enabling Technology for High-Power Applications. Proc. IEEE 2009, 97, 1786-1817. [CrossRef]

8. Naouar, M.W.; Monmasson, E.; Naassani, A.A.; Slama-Belkhodja, I.; Patin, N. FPGA-Based Current Controllers for AC Machine Drives-A Review. IEEE Trans. Ind. Electron. 2007, 54, 1907-1925. [CrossRef]

9. Viola, F. Experimental evaluation of the performance of a three-phase five-level cascaded h-bridge inverter by means FPGA-based control board for grid connected applications. Energies 2018, 11, 3298. [CrossRef]

10. De, S.; Banerjee, D.; Kumar, K.S.; Gopakumar, K.; Ramchand, R.; Patel, C. Multilevel inverters for low-power application. IET Power Electron. 2011, 4, 384-392. [CrossRef]

11. Ala, G.; Caruso, M.; Miceli, R.; Pellitteri, F.; Schettino, G.; Trapanese, M.; Viola, F. Experimental investigation on the performances of a multilevel inverter using a field programmable gate array-based control system. Energies 2019, 12, 1016. [CrossRef]

12. Schettino, G.; Benanti, S.; Buccella, C.; Caruso, M.; Castiglia, V.; Cecati, C.; Di Tommaso, A.O.; Miceli, R.; Romano, P.; Viola, F. Simulation and experimental validation of multicarrier PWM techniques for three-phase five-level cascaded H-bridge with FPGA controller. Int. J. Renew. Energy Res. 2017, 7, 1383-1394.

13. Miceli, R.; Schettino, G.; Viola, F. A novel computational approach for harmonic mitigation in PV systems with single-phase five-level CHBMI. Energies 2018, 11, 2100. [CrossRef]

14. Marquez, A.; Leon, J.I.; Vazquez, S.; Portillo, R.; Franquello, L.G.; Freire, E.; Kouro, S. Variable-Angle Phase-Shifted PWM for Multilevel Three-Cell Cascaded H-Bridge Converters. IEEE Trans. Ind. Electron. 2017, 64, 3619-3628. [CrossRef]

15. Grigoletto, F.B.; Pinheiro, H. Generalised pulse width modulation approach for DC capacitor voltage balancing in diode-clamped multilevel converters. IET Power Electron. 2011, 4, 89-100. [CrossRef]

16. Holmes, G.; Lipo, T.A. Pulse Width Modulaiton for Power Converters: Principle and Practice; IEEE Press: Piscataway, NJ, USA, 2003.

17. Wells, J.R.; Geng, X.; Chapman, P.L.; Krein, P.T.; Nee, B.M. Modulation-Based Harmonic Elimination. IEEE Trans. Power Electron. 2007, 22, 336-340. [CrossRef]

18. De Boor, C. Approximation Theory; American Mathematical Society: New Orleans, LA, USA, 1986; Volume 36.

19. De Boor, C. A Practical Guide to Splines; Springer: New York, NY, USA, 2001; ISBN 0387953663. 
20. Saleh, S.A.; Rahman, M.A. Development and Experimental Testing of a Single-Phase B-Spline-Based SPWM Inverter. In Proceedings of the 2006 IEEE International Symposium on Industrial Electronics, Montreal, QC, Canada, 9-13 July 2006; pp. 815-819.

21. Saleh, S.A.; Rahman, M.A. Discrete time-based model of the sinusoidal pulse width modulation technique. In Proceedings of the 31st Annual Conference of IEEE Industrial Electronics Society, Raleigh, NC, USA, 6-10 November 2005; p. 6.

22. Saleh, S.A.; Rahmen, M.A. Experimental testing of a novel control for inverter-fed three-phase induction motor. In Proceedings of the 2006 IEEE Power Engineering Society General Meeting, Montreal, QC, Canada, 18-22 June 2006; p. 5. [CrossRef]

23. Genduso, R.; Miceli, R.; Rando, C. Algebraic real-time algorithm for B-Spline sinusoidal pulse width modulation in three phase voltage source inverters. In Proceedings of the 2008 IEEE International Symposium on Industrial Electronics, Cambridge, UK, 30 June-2 July 2008; pp. 353-358.

24. Genduso, R.; Miceli, R.; Rando, C. Implementation and experimental validation of a real-time PWM algorithm based on B-Spline carriers for three phase voltage source inverters. In Proceedings of the 2009 IEEE International Symposium on Industrial Electronics, Seoul, Korea, 5 June-8 July 2009; pp. 1829-1834.

25. Di Tommaso, O.; Genduso, F.; Miceli, R.; Raciti, A. A reexamination of voltage distortion for classical carrier-based vs B-Spline modulation of three-phase Voltage Sources Inverters. In Proceedings of the 2015 IEEE 24th International Symposium on Industrial Electronics (ISIE), Buzios, Brazil, 3-5 June 2015; pp. 986-991.

26. Schettino, G.; Castiglia, V.; Genduso, F.; Livreri, P.; Miceli, R.; Romano, P.; Viola, F. Simulation of a single-phase five-level cascaded H-Bridge inverter with multicarrier SPWM B-Spline based modulation techniques. In Proceedings of the 2017 Twelfth International Conference on Ecological Vehicles and Renewable Energies (EVER), Monte Carlo, Monaco, 11-13 April 2017; pp. 1-6.

27. Castiglia, V.; Livreri, P.; Miceli, R.; Raciti, A.; Schettino, G.; Viola, F. Performances of a three-phase five-level cascaded H-bridge inverter with phase shifted B-spline based modulation techniques. In Proceedings of the 2017 IEEE 6th International Conference on Renewable Energy Research and Applications (ICRERA), San Diego, CA, USA, 5-8 November 2017; pp. 1192-1197.

28. Cohen, A.; Daubechies, I.; Vial, P. Multiresolution analysis, wavelets and fast algorithms on an interval. Appl. Comput. Harmon. Anal. 1993, 1, 100-115.

29. Cohen, A.; Daubechies, I.; Vial, P. Wavelets on the interval and fast wavelet transform. Appl. Comput. Harmon. Anal. 1993, 1, 54-81. [CrossRef]

30. Ala, G.; Francomano, E.; Viola, F. A wavelet operator on the interval in solving Maxwell's equations. Prog. Electromagn. Res. Lett. 2011, 27, 133-140. [CrossRef]

31. Barmada, S.; Musolino, A.; Raugi, M. Wavelet-based time-domain solution of multiconductor transmission lines with skin and proximity effect. IEEE Trans. Electromagn. Compat. 2005, 47, 774-780. [CrossRef]

32. Barmada, S.; Musolino, A.; Raugi, M. Analysis of Integrated circuit systems by an innovative wavelet-based scattering matrix approach. IEEE Trans. Adv. Packag. 2007, 30, 86-96. [CrossRef]

33. Daubechies, I. Ten Lectures on Wavelets; SIAM: Philadelphia, PA, USA, 1992; p. 12.

34. Rubinacci, G.; Tamburrino, A.; Ventre, S.; Villone, S. Interpolating wavelets for the solution of Maxwell equations in the time domain. IEEE Trans. Magn. 1998, 34, 2775-2778. [CrossRef]

35. Carrara, G.; Gardella, S.; Marchesoni, M.; Salutari, R.; Sciuto, G. A new multilevel PWM method: A theoreotical analysis. IEEE Trans. Power Electron. 1992, 7, 497-505. [CrossRef]

36. McGrath, B.P.; Holmes, D.G. Multicarrier PWM strategies for multilevel inverters. IEEE Trans. Ind. Electron. 2002, 49, 858-867. [CrossRef]

37. Balamurugan, C.R.; Natarajan, S.P.; Bensraj, R.; Shanthi, B. A Review on Modulation Strategies of Mulilevel Inverter. Indones. J. Electr. Eng. Comput. Sci. 2016, 3, 681-705. [CrossRef]

(C) 2019 by the authors. Licensee MDPI, Basel, Switzerland. This article is an open access article distributed under the terms and conditions of the Creative Commons Attribution (CC BY) license (http://creativecommons.org/licenses/by/4.0/). 